\title{
MIPAS detection of cloud and aerosol particle occurrence in the UTLS with comparison to HIRDLS and CALIOP
}

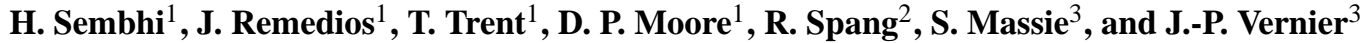 \\ ${ }^{1}$ Earth Observation Science, Space Research Centre, Physics and Astronomy, University of Leicester, Leicester, UK \\ ${ }^{2}$ Institute for Energy and Climate Research - Stratosphere (IEK-7), Forschungszentrum Jülich, 52425 Jülich, Germany \\ ${ }^{3}$ NASA Langley Research Center, Hampton, Virginia, USA
}

Correspondence to: H. Sembhi (hs32@le.ac.uk)

Received: 7 January 2012 - Published in Atmos. Meas. Tech. Discuss.: 22 February 2012

Revised: 1 August 2012 - Accepted: 25 September 2012 - Published: 26 October 2012

\begin{abstract}
Satellite infrared emission instruments require efficient systems that can separate and flag observations which are affected by clouds and aerosols. This paper investigates the identification of cloud and aerosols from infrared, limb sounding spectra that were recorded by the Michelson Interferometer for Passive Atmospheric Sounding (MIPAS), a high spectral resolution Fourier transform spectrometer on the European Space Agency's (ESA) ENVISAT (Now inoperative since April 2012 due to loss of contact). Specifically, the performance of an existing cloud and aerosol particle detection method is simulated with a radiative transfer model in order to establish, for the first time, confident detection limits for particle presence in the atmosphere from MIPAS data. The newly established thresholds improve confidence in the ability to detect particle injection events, plume transport in the upper troposphere and lower stratosphere (UTLS) and better characterise cloud distributions utilising MIPAS spectra. The method also provides a fast front-end detection system for the MIPClouds processor; a processor designed for the retrieval of macro- and microphysical cloud properties from the MIPAS data.

It is shown that across much of the stratosphere, the threshold for the standard cloud index in band A is 5.0 although threshold values of over 6.0 occur in restricted regimes. Polar regions show a surprising degree of uncertainty at altitudes above $20 \mathrm{~km}$, potentially due to changing stratospheric trace gas concentrations in polar vortex conditions and poor signal-to-noise due to cold atmospheric temperatures. The optimised thresholds of this study can be used for much of the time, but time/composition-dependent thresholds are recommended for MIPAS data for the strongly perturbed polar
\end{abstract}

stratosphere. In the UT, a threshold of 5.0 applies at $12 \mathrm{~km}$ and above but decreases rapidly at lower altitudes. The new thresholds are shown to allow much more sensitive detection of particle distributions in the UTLS, with extinction detection limits above $13 \mathrm{~km}$ often better than $10^{-4} \mathrm{~km}^{-1}$, with values approaching $10^{-5} \mathrm{~km}^{-1}$ in some cases.

Comparisons of the new MIPAS results with cloud data from HIRDLS and CALIOP, outside of the poles, establish a good agreement in distributions (cloud and aerosol top heights and occurrence frequencies) with an offset between MIPAS and the other instruments of $0.5 \mathrm{~km}$ to $1 \mathrm{~km}$ between $12 \mathrm{~km}$ and $20 \mathrm{~km}$, consistent with vertical oversampling of extended cloud layers within the MIPAS field of view. We conclude that infrared limb sounders provide a very consistent picture of particles in the UTLS, allowing detection limits which are consistent with the lidar observations. Investigations of MIPAS data for the Mount Kasatochi volcanic eruption on the Aleutian Islands and the Black Saturday fires in Australia are used to exemplify how useful MIPAS limb sounding data were for monitoring aerosol injections into the UTLS. It is shown that the new thresholds allowed such events to be much more effectively derived from MIPAS with detection limits for these case studies of $1 \times 10^{-5} \mathrm{~km}^{-1}$ at a wavelength of $12 \mu \mathrm{m}$.

\section{Introduction}

High altitude clouds play a fundamental role in the Earth system through their influence on climate and the Earth's energy balance (Forster et al., 2007). Such cloud formations and 
types are characterised by different ice crystal sizes, shapes and particle densities and are influenced by local temperature and humidity conditions. The combination of colder temperatures and lower humidities in the tropical UTLS region gives rise to layers of thin cirrus, composed mainly of ice crystals, that have radiative implications for the tropical tropopause layer (TTL) (Jensen et al., 1996a). The presence and formation of thin tropical cirrus clouds may be important to understand the processes affecting stratospheric dehydration (Jensen et al., 1996b) as well as being indicative of regions of deep convection (Liu et al., 2007). In the polar regions, understanding the composition and occurrence of the polar stratospheric clouds (PSCs) is important for their role in ozone $\left(\mathrm{O}_{3}\right)$ depletion at the poles (Manney et al., 2011).

Atmospheric aerosols are ubiquitous in nature and originate from natural and anthropogenic processes such as burning of savannah and crops, volcanic eruptions and industrial burning (Stephens, 1994). Aerosols can be lofted into the UTLS in several ways. Pyro-convection, a combination of extreme convection and forest fires that manifests within pyro-cumulonimbus (pyroCb) clouds (Fromm et al., 2006), has the potential to uplift aerosols directly into the stratosphere. Another mechanism that can potentially cause stratospheric injection into the UTLS is through isentropic transport caused by solar radiation absorption of aerosols (de Laat et al., 2012). Explosive volcanic eruptions can also inject polluted material - including ash, sulphur dioxide $\left(\mathrm{SO}_{2}\right)$, carbon dioxide $\left(\mathrm{CO}_{2}\right)$ and water vapour $\left(\mathrm{H}_{2} \mathrm{O}\right)$ - directly into the UTLS with resulting plumes being transported across the globe (Prata et al., 2007; Clarisse et al., 2008). If injected into the stratosphere, $\mathrm{SO}_{2}$ can become oxidised and hydrated, leading to the formation of sulphuric acid $\left(\mathrm{H}_{2} \mathrm{SO}_{4}\right)$ droplets within a few weeks of the eruptions (Prata et al., 2010).

Understanding the global and localised distribution of such a variety of cloud formations and aerosols is particularly important for modelling climate radiative forcing (Randall et al., 2007), for investigating cloud-chemistry interactions such as chlorine activation in the polar stratosphere (Manney et al., 2011), and determining the radiative implications that high cirrus clouds or aerosol enhancements can have on the radiative balance in the UTLS (Robock, 2000; Corti et al., 2005). Detection of cloud and enhanced aerosol is also an essential component for all satellite remote sensing instruments; accurate and robust cloud detection methods not only determine the quality of satellite retrievals (for example, greenhouse gas concentrations, land and sea surface temperatures) but are also valuable as a pre-processor for retrieval of cloud properties.

Cloud detection techniques are generally well-established for nadir spaceborne instruments in which the detection is loosely based on brightness temperature differences (BTD) or reflectance ratios, for thermal and visible sounders, respectively (Frey et al., 2008). Strabala et al. (1994) demonstrated how the BTD of $8 \mu \mathrm{m}$ and $11 \mu \mathrm{m}$, and of $11 \mu \mathrm{m}$ and $12 \mu \mathrm{m}$, can distinguish between cirrus and water clouds using brightness temperature measurements from the High Resolution Infrared Sounder (HIRS) and the Advanced Very High Resolution Radiometer (AVHRR). Although passive nadir sounders are well-equipped to measure clouds globally due to their high horizontal resolution, their limited vertical resolution cannot resolve cloud top heights with high accuracy (Weisz et al., 2007). Active nadir sounders offer much higher vertical resolution. The Cloud-Aerosol LIdar with Orthogonal Polarization (CALIOP) lidar on board NASA's CloudAerosol Lidar and Infrared Pathfinder Satellite Observation (CALIPSO) offers vertical resolution better than $180 \mathrm{~m}$ and therefore provides the most detailed spaceborne measurements of clouds currently available (Winker et al., 2007).

The limb sounding technique offers some distinct attributes for the investigation of clouds in the UTLS due to (a) the fine vertical resolution achieved (up to $1 \mathrm{~km}$ ) and (b) high sensitivity to low aerosol particle amounts due to the long integrating path of the limb.

Atmospheric radiances from a range of limb sounding instruments have been used to study cloud signatures. These include the Stratospheric Aerosol and Gas Experiment (SAGE) instrument series (Kent et al., 1993), the Optical Spectrograph and InfraRed Imaging System (OSIRIS) on the Swedish ODIN satellite (Bourassa et al., 2005) and the SCanning Imaging Absorption spectrometer for Atmospheric CartograpHY (SCIAMACHY) instrument on ENVISAT (Eichmann et al., 2009) with observations made in the ultraviolet to shortwave infrared (UV-SWIR) or the near infrared (NIR) spectral range. Alternatively, the HALogen Occultation Experiment (HALOE) on the Upper Atmosphere Research Satellite (UARS) utilised the mid-infrared range of the spectrum (Hervig and McHugh, 1999). The current Atmospheric Chemistry Experiment (ACE-FTS), a wide range spectrometer, observes clouds in the mid- to thermal infrared spectral range but with a limited measurement network due to its operation in solar occultation mode.

The sub-millimetre wavelength region should also be mentioned as it has been used to sense clouds deeper into the troposphere and of higher cloud opacity as shown by the NASA Microwave Limb Sounder (MLS) missions (Wu and Jiang, 2004).

Limb instruments that sense in the thermal emission part of the electromagnetic spectrum provide measurements in both day and night conditions, with the possibility of obtaining, from some instruments, highly resolved cloud spectra, from which particle radius, volume distributions and cloud composition can be determined. Such infrared sensors have included narrowband spectrometers such as the Cyrogenic Limb Array Etalon Spectrometer (CLAES); wide range spectrometers such as the CRyogenic Infrared Spectrometers and Telescopes for the Atmosphere (CRISTA), which observed atmospheric emission spectra in the $4 \mu \mathrm{m}$ to $12 \mu \mathrm{m}$ range; and wideband limb radiometers such as the HIgh Resolution Dynamics Limb Sounder (HIRDLS) $(6.12 \mu \mathrm{m}$ to $17.76 \mu \mathrm{m})$ that was flown on the EOS AURA platform within the 
NASA "A Train". Mergenthaler et al. (1999) and Spang et al. (2002) demonstrated that the signatures of ice and water clouds can be captured by highly-resolved spectra covering the $12 \mu \mathrm{m}$ spectral region as demonstrated with the CLAES and CRISTA instruments, respectively. Analysis of HIRDLS data has confirmed that infrared emission is highly suited for the study of cloud heights, especially in the tropics (Massie et al., 2010). A full review of cloud measurements from infrared, limb sounding instruments can be found in Hurley et al. (2011).

An instrument that offered both detailed coverage of the UTLS and high spectral resolution is MIPAS, which obtained atmospheric emission spectra, near-continuously, since its launch on the ENVISAT platform on 1 March 2002. It achieved close to $10 \mathrm{yr}$ of operation, allowing the time evolution of UTLS clouds to be monitored in a way that had not been possible with previous infrared limb sensors.

The objective of this paper is to establish new and systematic detection thresholds for the effects of clouds and aerosols so as to better describe the UTLS distributions of clouds and aerosols. The structure of this paper is as follows. An introduction to the MIPAS instrument and comparative instrumentation is followed by a brief summary of the current operational MIPAS cloud detection scheme. The methodology to enhance the ability to detect optically thick and thin clouds and atmospheric aerosols using MIPAS is described and finally some results and case studies are shown in Sect. 6 to demonstrate the performance of the detection method.

\section{The MIPAS instrument}

MIPAS was a thermal infrared Fourier transform spectrometer that measured day and night atmospheric limb emission spectra in the $685 \mathrm{~cm}^{-1}$ to $2410 \mathrm{~cm}^{-1}$ spectral range over 5 broadbands (band A: $685-970 \mathrm{~cm}^{-1}$, AB: 1020 $1170 \mathrm{~cm}^{-1}$, B: $1215-1500 \mathrm{~cm}^{-1}, \mathrm{C}: 1570-1750 \mathrm{~cm}^{-1}$ and D: $1820-2410 \mathrm{~cm}^{-1}$ ). Spectra were routinely calibrated by an onboard blackbody for the determination of the gain function, while deep space measurements were used to characterise its offset function. From launch to March 2004, MIPAS observed the atmosphere in "Full Resolution" (FR) mode by sensing the atmosphere from $68 \mathrm{~km}$ to $6 \mathrm{~km}$ with a $3 \mathrm{~km}$ vertical resolution (through a trapezoidal field of view (FOV) with $4 \mathrm{~km}$ base and $2.8 \mathrm{~km}$ top) and $0.025 \mathrm{~cm}^{-1}$ (unapodised) spectral resolution. The Noise Equivalent Spectral Radiance (NESR) for this measurement mode remained well below the pre-flight requirement of $50 \mathrm{nW} /\left(\mathrm{cm}^{2} \mathrm{srcm}^{-1}\right)$ in band A as reported in Kleinert et al. (2007). After this the instrument configuration was modified to overcome accumulating anomalies associated with moving retro-reflectors within the interferometer (Fischer et al., 2008). The "Optimised Resolution" (OR) mode came into effect from 9 January 2005 to 8 April 2012 with the spectral resolution changed to $0.0625 \mathrm{~cm}^{-1}$ (unapodised), a reduction in the NESR, and a nominal sampling of $1.5 \mathrm{~km}$ in the UTLS with operations starting at a $35 \%$ duty cycle, upgrading to $100 \%$ duty cycle from December 2007.

The instrument provided good coverage of the Poles, up to $89.3^{\circ}$ north and south, with measurements made at local solar times of 10:30 and 22:30 day and night. This, combined with its various scan patterns (Fischer et al., 2008), allowed different regions of the atmosphere (thermosphere, and mesosphere for example) to be sensed whilst providing good coverage of the UTLS, albeit with some gaps when upper atmosphere modes were enabled. It is in the UTLS that the distribution and evolution of cloud structures can be investigated, with MIPAS spectra potentially providing information about the macro- and microphysical properties such as cloud top height, occurrence frequencies, ice water content and particle size.

\section{Contemporaneous satellite instruments}

Two instruments are used in this study to verify MIPAS detection of clouds and aerosols: HIRDLS and CALIOP. These instruments are selected because they provide the highest vertical resolutions for clouds and aerosols in the UTLS of all the relevant satellite instruments whilst also observing at the same time as the MIPAS instrument. The HIRDLS data (in an earlier version) and CALIOP data have previously been compared in a study by Massie et al. (2010) and were shown to display similar cloud occurrence frequencies.

\subsection{HIRDLS}

The HIRDLS instrument operated between 22 January 2005 and 17 March 2008, offering an overlap period (approximately 26.5 months) with the MIPAS instrument. Following its launch on the EOS Aura spacecraft, the HIRDLS instrument showed anomalously high radiance measurements discovered to be a result of a large blockage in the HIRDLS FOV. The instrument was reconfigured and correction algorithms dealing with the blockage anomalies were applied to produce measurements with a vertical resolution of $1.5 \mathrm{~km}$ and along-track profile spacing of approximately $100 \mathrm{~km}$. Due to the blockage, the HIRDLS scan pattern was restricted to a single azimuth angle of $47^{\circ}$ from the anti-flight direction with the measurements located between $87^{\circ} \mathrm{N}$ and $63^{\circ} \mathrm{S}$.

HIRDLS cloud data are produced from channel 6 , the $12.1 \mu \mathrm{m}$ radiance channel, in two forms; one is a cloud flag and the other consists of $12 \mu \mathrm{m}$ extinction profiles. The "12MicronCloudFlag" is produced by analysis of enhancements along each calibrated HIRDLS radiance profile. Different regions and intensities of enhancements represent particular cloud types and flags are assigned as: $0=$ clear sky, $1=$ unknown cloud type, $2=$ cirrus layer, $3=$ extensive PSCs and $4=$ opaque clouds. Polar stratospheric clouds and tropical sub-visible cirrus cloud extinctions range from 
approximately $10^{-4}$ to $10^{-2} \mathrm{~km}^{-1}$. The unknown cloud label accounts for radiance perturbations at non-polar locations that may be influenced by volcanic or forest fire smoke clouds in the UTLS (Massie et al., 2007, 2010; Gille et al., 2011).

Extinction profiles are retrieved using an optimal estimation technique, starting with the retrieval of a temperature profile which is fed into the retrieval of cloud and aerosol extinction over the full altitude range for each HIRDLS radiance profile. Trace gas estimates come from a Modelling of OZone And Related chemical Tracers (MOZART) climatology and the a priori estimate of cloud/aerosol extinction comes from a SAGE mid-latitude extinction profile.

Gille et al. (2011) recommend several selection criteria for the best quality HIRDLS cloud data. These include extraction of all extinction profiles with corresponding flags between 1 and 4 , extinctions between $1 \times 10^{-2} \mathrm{~km}^{-1}$ and $9 \times 10^{-5} \mathrm{~km}^{-1}$, extinction precisions that should be between $0 \%$ and $100 \%$, and no usage of data outside of the pressure range of $215 \mathrm{hPa}$ and $20 \mathrm{hPa}$.

\subsection{CALIOP}

CALIOP lidar, along with HIRDLS, forms part of the NASA "A-TRAIN" suite of instruments for which the equatorial crossing time is $1: 30$ and 13.30. CALIOP is a nadir dual-wavelength and dual-polarization space lidar, using the $532 \mathrm{~nm}$ and $1064 \mathrm{~nm}$ regions to observe the backscatter signals of the Earth's atmosphere from the near-surface to $30 \mathrm{~km}$. It has a variable vertical resolution of $30 \mathrm{~m}$ from the ground to $8.2 \mathrm{~km}, 60 \mathrm{~m}$ from $8.2 \mathrm{~km}$ to $20.2 \mathrm{~km}$ in the UTLS, and $180 \mathrm{~m}$ from $20.2 \mathrm{~km}$ to $30.1 \mathrm{~km}$ (Winker et al., 2006). Backscatter profiles collected by CALIOP can resolve the vertical structure and properties of clouds and aerosols with a high vertical resolution, providing extremely valuable information on the variation and vertical extent of clouds and aerosols (Winker et al., 2010). A range of scientific products are available from CALIOP, including profile and layer backscatter for clouds and aerosols, cloud and aerosol layer top heights as well extinction and optical depth profiles. Level 2 cloud and aerosol profiles from CALIOP are reported on a $60 \mathrm{~m}$ vertical grid with $5 \mathrm{~km}$ horizontal resolution (Vaughan et al., 2004). Data from nighttime overpasses are generally "cleaner" than daytime as the noise levels are larger during daytime due to increased background solar radiation.

\section{MIPAS cloud detection}

MIPAS spectra respond to clouds that are in its line of sight in a very distinctive manner. Figure 1 shows MIPAS cloud-free, thin cirrus and optically thick cloud spectra taken from orbit 37927 at $16 \mathrm{~km}$ within the $750 \mathrm{~cm}^{-1}$ to $870 \mathrm{~cm}^{-1}$ wavenumber range in band $\mathrm{A}$. The spectral radiances are

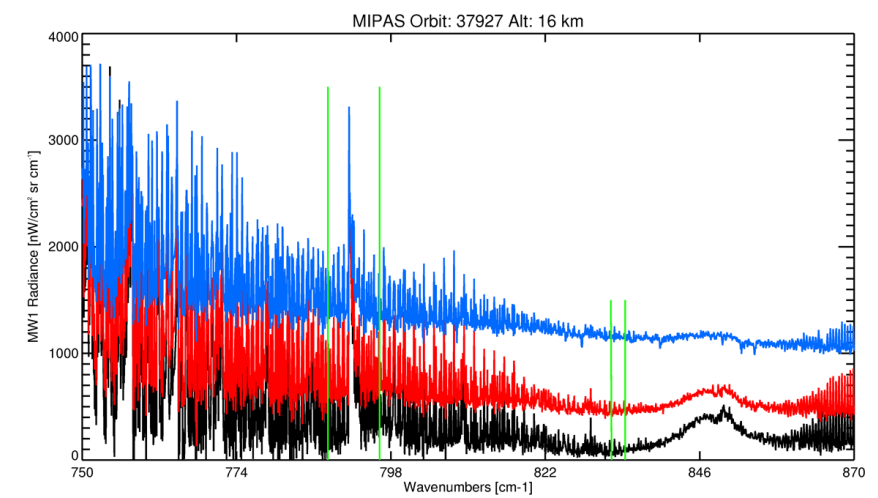

Fig. 1. MIPAS L1b spectra collected from orbit 37927 at $16 \mathrm{~km}$ within the spectral region of $750 \mathrm{~cm}^{-1}$ to $870 \mathrm{~cm}^{-1}$. The colours indicate cloud-free spectra (black), thin cloud spectra (red) and optically thick cloud spectra (blue). Thick cloud spectra become heavily offset due to the change in baseline radiance combined with a loss of spectral features. Such radiances changes are more apparent in the region close to $832 \mathrm{~cm}^{-1}$ relative to those observed between $788 \mathrm{~cm}^{-1}$ and $796 \mathrm{~cm}^{-1}$ (indicated by the vertical green lines).

strongly offset due to the additional broadband emission from clouds. Optically thick clouds exhibit strong baseline offsets in MIPAS spectra accompanied by either reduced spectral features or scattering lines under certain regimes (Höpfner et al., 2002). The largest radiance differences due to cloud occurs in the $820 \mathrm{~cm}^{-1}$ to $950 \mathrm{~cm}^{-1}$ within band $\mathrm{A}$, as well as some effects in bands B and D, at $1225 \mathrm{~cm}^{-1}$ to $1245 \mathrm{~cm}^{-1}$ and $1970 \mathrm{~cm}^{-1}$ to $1985 \mathrm{~cm}^{-1}$, respectively. These cloudy spectra contain a wealth of information from which cloud information can be derived, as summarised in Spang et al. (2012), including composition of PSCs (Spang and Remedios, 2003) and cloud top height (Hurley et al., 2011).

The cloud index (CI) is a simple and robust cloud detection ratio (Spang et al., 2004) that takes into account these characteristic radiance changes. It is calculated using small specially-selected spectral regions, or microwindow pairs, that consist of a "control region" dominated by well-mixed $\mathrm{CO}_{2}$ and a "cloud/aerosol" dominated spectral region with weak trace gases emissions, for example in band $\mathrm{A}$, from $\mathrm{O}_{3}$, nitric acid $\left(\mathrm{HNO}_{3}\right)$ and chlorofluorocarbon 11 (CFC-11). A number of such pairs have been defined (Raspollini et al., 2006) for the purpose of identifying spectra in which clouds and aerosols might contaminate trace gas retrievals, producing erroneous data. The cloud spectral regions and detection thresholds for MIPAS bands A, B and D are shown in Table 1 . These CI thresholds were used for cloud-clearing in the operational trace gas retrievals for MIPAS. However, a number of studies have used higher thresholds to be more conservative. For example, Milz et al. (2005) and Moore et al. (2012) increased the CI for band A (CI-A) threshold to a fixed value of 4.0 to exclude optically thinner cloud contamination prior to MIPAS trace gas retrievals. 
Table 1. Spectral regions of operational CI thresholds for cloudclearing of MIPAS trace gas retrievals (Raspollini et al., 2006).

\begin{tabular}{lccc}
\hline $\begin{array}{l}\text { MIPAS } \\
\text { band }\end{array}$ & $\begin{array}{c}\text { MW1 } \\
\left(\mathrm{cm}^{-1}\right)\end{array}$ & $\begin{array}{c}\text { MW2 } \\
\left(\mathrm{cm}^{-1}\right)\end{array}$ & Threshold \\
\hline CI-A & $788.20-796.25$ & $832.3-834.4$ & 1.8 \\
CI-B & $1246.3-1249.1$ & $1232.2-1234.4$ & 1.2 \\
CI-D & $1929.0-1935.0$ & $1973.0-1983.0$ & 1.8 \\
\hline
\end{tabular}

The CI-A data themselves contain key information on the characteristics of the atmosphere and band A provides the best combination of clear atmospheric windows for detection and signal-to-noise for cloud/aerosol particle effects. A number of studies have used this region for the retrieval of cloud properties, as shown by Höpfner et al. $(2002,2006)$, and Hurley et al. (2011). For a more comprehensive review of cloud identification methods and their use in cloud parameter retrievals from MIPAS, the reader is referred to Spang et al. (2012). In this study, we focus on CI-A as the cloud index associated with this band.

Observed frequency distributions of CI-A tend to follow a distinctive bi-modal behaviour where cloud/aerosol saturated radiances peak close to $\mathrm{CI}-\mathrm{A}$ values of approximately 1.5. Closer to 6.0, the CI-A values characterise what might be expected from cloud-free measurements, an observation supported by radiative transfer simulations for trace gas only atmospheres. Spang et al. (2004) noted that CI-A values are less than 2.0 for thick opaque cloudy spectra and usually greater than 5.0 for cloud-free; values between 2.0 and 5.0 are associated with optically thinner cirrus clouds or aerosol. Recently, Höpfner et al. (2009) used a fixed threshold of 4.5 to detect PSCs.

The CI detection method works well within the UTLS region where it can capture the signatures of cirrus and PSCs but it does have some limitations. Spang et al. (2002) and Greenhough et al. (2005) found that upper tropospheric $\mathrm{H}_{2} \mathrm{O}$ can give rise to CI-A values similar to those of clouds and that it can be difficult to distinguish between the two at lower altitudes (below $9 \mathrm{~km}$ ). At higher altitudes (close to $30 \mathrm{~km}$ ) the CI method starts to become less valid as the radiances decrease and the influence of instrument noise becomes more apparent. The sensitivity of this CI behaviour to clouds and aerosol can be maximised by improving the thresholds of detection. Such thresholds should successfully trap out the variable atmospheric trace gas signatures from the cloud and aerosol signatures in the radiances, essentially acting as a "barrier" between particles and trace gases. In this study we derive suitable thresholds, and for the first time for MIPAS, we systematically focus the studies on the detection of cloud/aerosols rather than simply flagging cloudy spectra for trace-gas retrieval purposes.

\section{A simulation method for improved detection thresholds}

To find suitable thresholds for MIPAS cloud and aerosol detection, a simulation approach was employed in which MIPAS spectral microwindows were modelled using a radiative transfer model. This required knowledge of global and seasonally varying atmospheric trace gases, upper tropospheric $\mathrm{H}_{2} \mathrm{O}$ variability and MIPAS characteristics. Furthermore, such a method allows appropriate thresholds to be determined independently from real MIPAS spectral data.

The simulations were performed as follows: a set of CI microwindow radiances were simulated using the Reference Forward Model (RFM), a line-by-line radiative transfer model developed at the University of Oxford specifically for the simulation MIPAS spectra (Dudhia, 2005). From each pair of CI microwindows, an index was calculated that effectively acts like a "gas index". As cloud and enhanced aerosol were excluded in the simulations, the calculated indices represent the sensitivity of CI with respect to trace gas variability in the atmosphere; the approach of finding the "gas limit" also has the advantage of not requiring the modelling of clouds and aerosols in the radiative transfer model. Using indices from an ensemble of simulations, optimised cloud detection thresholds were generated for a range of latitude and altitude regions as described in the following sections.

\subsection{Simulation characteristics}

Version 4.28 of the RFM was used for the simulation of MIPAS-like radiances in which calculations are based on the transmittance for each gas that contributes to the spectral region of interest. Spectral calculations are performed on a fine mesh grid of $0.0005 \mathrm{~cm}^{-1}$ resolution and interpolated internally onto a user-defined wavenumber range and resolution. Voigt line shapes and atmospheric $\mathrm{H}_{2} \mathrm{O}$ continuum are represented within the simulations and local thermodynamic equilibrium (LTE) of the atmosphere is assumed.

Table 2 summarises the input and simulation setup used for calculations for the CI-A spectral microwindows. A realistic representation of background trace gases is of key importance and these came from the Reference Atmospheres for MIPAS: Standard Atmospheres (RAMstan) climatological database that contains temperature, pressure and concentration profiles of up to 36 atmospheric constituents (Remedios et al., 2007). Profiles can be chosen either (a) from version 3.1 of the Standard Atmospheres database that describe mean concentrations over 5 latitude bands $\left(90^{\circ}\right.$ to $30^{\circ} \mathrm{N} / \mathrm{S}$, $60^{\circ}$ to $30^{\circ} \mathrm{N} / \mathrm{S}, 30^{\circ}$ to $30^{\circ} \mathrm{N} / \mathrm{S}$ ) with estimates of extreme conditions (given by maximum and minimum profiles) or (b) from version 4 of the Initial Guess 2 (IG2) climatology that contain profiles varying latitudinally over six bands that are $90^{\circ}$ to $65^{\circ} \mathrm{N} / \mathrm{S}, 65^{\circ}$ to $20^{\circ} \mathrm{N} / \mathrm{S}$ and $20^{\circ}$ to $0^{\circ} \mathrm{N} / \mathrm{S}$ and seasonally for January, April, July and October. As it has been shown that upper tropospheric $\mathrm{H}_{2} \mathrm{O}$ can produce $\mathrm{CI}$ values 
Table 2. Details of MIPAS cloud microwindow simulations.

\begin{tabular}{|c|c|}
\hline \multicolumn{2}{|c|}{ Simulations With the Oxford Reference Forward Model } \\
\hline Microwindows & $\begin{array}{l}\text { MW1 }=788.20-796.25 \mathrm{~cm}^{-1} \\
\text { MW2 }=832.3-834.4 \mathrm{~cm}^{-1}\end{array}$ \\
\hline Instrument characteristics & $\begin{array}{l}\text { Apodised instrument line shape (ILS) and MIPAS FOV convolutions at each spectral and tangent } \\
\text { height calculation }\end{array}$ \\
\hline Trace gas climatology & $\begin{array}{l}\text { Leicester RAMstan IG2 climatological database for temperature (K), pressure (hPa) and } \\
\text { concentration profiles of } \mathrm{CO}_{2}, \mathrm{O}_{3}, \mathrm{~N}_{2} \mathrm{O}, \mathrm{CO}, \mathrm{CH}_{4}, \mathrm{O}_{2}, \mathrm{NO}, \mathrm{NO}_{2}, \mathrm{HNO}_{3}, \mathrm{ClO}, \mathrm{N}_{2}, \mathrm{~F} 11, \mathrm{~F} 12, \mathrm{~F} 22 \text {, } \\
\mathrm{CCl}_{4}, \mathrm{~N}_{2} \mathrm{O}_{5} \text { and } \mathrm{ClONO}_{2} \\
\text { Latitude bands: } 90^{\circ} \text { to } 65^{\circ} \mathrm{N} / \mathrm{S}, 65^{\circ} \text { to } 20^{\circ} \mathrm{N} / \mathrm{S} \text { and } 20^{\circ} \text { to } 0^{\circ} \mathrm{N} / \mathrm{S} \\
\text { Seasons: January, April, July, October }\end{array}$ \\
\hline Background aerosol & $\begin{array}{l}\text { Latitudinally averaged extinction profiles retrieved from MIPAS spectra using the Optimal } \\
\text { Estimation Retrieval Algorithm or OPERA (Moore et al., 2008). The profiles are extended up to } \\
30 \mathrm{~km} \text { by merging with a scaled "background" extinction profile from HALOE. }\end{array}$ \\
\hline $\begin{array}{l}\text { Water vapour } \\
\text { representation }\end{array}$ & $\begin{array}{l}\text { Profiles are calculated from saturation vapour mixing ratio profiles using temperature and pressure } \\
\text { from the RAMSTAN climatology. Data used are from the minimum and mean Standard } \\
\text { Atmospheres, the mean IG2 temperature and pressure profiles per latitude band and the maximum } \\
\mathrm{H}_{2} \mathrm{O} \text { from the European Centre for Medium-Range Weather Forecasting (ECMWF). All saturation } \\
\text { vapour pressures are calculated using the Goff-Graatch formula (Vömel, 2011). } \mathrm{H}_{2} \mathrm{O} \text { continuum is } \\
\text { represented by the "MT_CKD_1.1" continuum model. }\end{array}$ \\
\hline $\begin{array}{l}\text { Altitude grid } \\
\text { Spectral and cross section }\end{array}$ & $\begin{array}{l}1 \mathrm{~km} \text { resolution from } 6 \text { to } 30 \mathrm{~km} \\
\text { "mipas_hitranpf3.3.bin" modified HITRAN database containing updated } \mathrm{C}_{2} \mathrm{H}_{6}, \mathrm{HNO}_{3} \text { line } \\
\text { information. }\end{array}$ \\
\hline
\end{tabular}

similar to those of clouds (Spang et al., 2004), it is important that the variation of $\mathrm{H}_{2} \mathrm{O}$ is well represented at lower altitudes.

$\mathrm{H}_{2} \mathrm{O}$ profiles used in the simulations consisted of concentration profiles calculated theoretically by considering the saturation mixing ratio that describes the maximum $\mathrm{H}_{2} \mathrm{O}$ that a parcel of air can hold at a chosen pressure and temperature. Profiles of saturation mixing ratio were calculated from the saturation vapour pressure (Vömel, 2011), with respect to liquid water and ice, for global RAMstan standard and IG2 pressure and temperature profiles. To verify the range of the calculated $\mathrm{H}_{2} \mathrm{O}$ concentrations, comparisons were made to ensembles of ECMWF $\mathrm{H}_{2} \mathrm{O}$ profiles for each latitude band from which the minimum, maximum and mean $\mathrm{H}_{2} \mathrm{O}$ concentrations were also extracted; theoretical $\mathrm{H}_{2} \mathrm{O}$ profiles from the RAMstan maximum standard atmosphere for each latitude band were found to be much larger than the maximum concentrations in the ECMWF ensembles and therefore removed from the analysis. As a result, the final $\mathrm{H}_{2} \mathrm{O}$ profiles used within each latitude band encompassed a combination of profiles calculated from mean and minimum RAMstan profiles as well as the maximum ECMWF concentration profiles.

\subsection{Calculation of improved thresholds}

The simulations provided an ensemble of theoretical radiances for the CI microwindows from which "gas only" index profiles were calculated for each IG2 latitude band. Using this information, the most effective way to determine the barrier between trace gas and cloud influence would be to derive a threshold based on the minimum index at each altitude from each ensemble of simulated index profiles. However, a further component to be accounted for in the calculation of the thresholds was the impact of random instrument noise through the MIPAS microwindows. For MIPAS, instrument noise was quantified by the NESR that varies in magnitude for each MIPAS band. Kleinert et al. (2007) reported that the NESR ranged from $50 \mathrm{nW} /\left(\mathrm{cm}^{2} \mathrm{sr} \mathrm{cm}^{-1}\right)$ in band $A$ to $3 \mathrm{nW} /\left(\mathrm{cm}^{2} \mathrm{srcm}^{-1}\right)$ in band D. Hence, the propagation of noise into each microwindow can be calculated as an uncertainty on the index. For each microwindow in question, the noise propagation was calculated by:

$\delta_{\mathrm{mw} i}=\frac{\mathrm{NESR}}{\sqrt{\mathrm{NPTS}_{\mathrm{mw} i}}}$,

where $i$ represents the microwindow, $\delta_{\mathrm{mw}}$ is the uncertainty due to noise calculated in the microwindow, NESR is the noise estimated in terms of radiance $\left(\mathrm{nW} /\left(\mathrm{cm}^{2} \mathrm{sr} \mathrm{cm}^{-1}\right)\right)$ for the band, and NPTS $\mathrm{mw}_{i}$ is the number of spectral points in the microwindow under analysis.

The uncertainty due to noise in both microwindows simulated $(\mathrm{MW} 1=$ microwindow 1 and $\mathrm{MW} 2=$ microwindow 2 ) was used to determine the contribution of noise on each index profile (Eq. 2) from which the absolute uncertainty on CI $\left(\sigma_{\mathrm{CI}}\right)$ was estimated (Eq. 3). 


$$
\begin{aligned}
\frac{\sigma_{\mathrm{CI}}}{\mathrm{CI}} & =\sqrt{\left(\frac{\delta_{\mathrm{mw} 1}}{\mathrm{MW} 1}\right)^{2}+\left(\frac{\delta_{\mathrm{mw} 2}}{\mathrm{MW} 2}\right)^{2}} \\
\sigma_{\mathrm{CI}} & =\mathrm{CI} \times \frac{\delta_{\mathrm{CI}}}{\mathrm{CI}}
\end{aligned}
$$

Finally, the optimal threshold (ThresopT) for each latitude band - accounting for natural trace gas variation, upper tropospheric $\mathrm{H}_{2} \mathrm{O}$ and instrument noise - was calculated as

Thres $_{\mathrm{OPT}}=$ Index $_{\min }-3 \sigma_{\mathrm{CI}}$,

where Index $x_{\min }$ is the minimum index value for each altitude in each set of ensemble calculations performed.

For the best representation of the NESR in the optimised thresholds, distributions of NESR (extracted from MIPAS L1b spectra) in MW1 and MW2 for both FR and OR modes were analysed. Generally, the NESR in the OR mode was found to be lower than that observed in the FR mode $\left(\sim 20 \mathrm{nW} /\left(\mathrm{cm}^{2} \mathrm{srcm}^{-1}\right)\right.$ compared to $\left.\sim 35 \mathrm{nW} /\left(\mathrm{cm}^{2} \mathrm{sr} \mathrm{cm}^{-1}\right)\right)$, and therefore a conservative estimate for the NESR of $30 \mathrm{nW} /\left(\mathrm{cm}^{2} \mathrm{srcm}^{-1}\right)$ was assumed in each microwindow. Typical values of $\sigma_{\mathrm{CI}}$ (corresponding to this NESR) were observed to be close to 0.5 at $15 \mathrm{~km}, 1.0$ at $20 \mathrm{~km}$ and up to 2.0 at $25 \mathrm{~km}$. Worst case values of $\sigma_{\mathrm{CI}}$ were 0.3 at $12 \mathrm{~km}, 1.0$ at $15 \mathrm{~km}, 2.0$ at $20 \mathrm{~km}$ and greater than or equal to 3.0 at altitudes above $25 \mathrm{~km}$ in polar winter.

The threshold profiles were then adjusted slightly to incorporate finer latitude banding over the mid-latitude and polar transition using a linear interpolation method. This means that the optimal threshold profiles represent the most conservative "clear sky" index value globally. Using these profiles, the presence of cloud or aerosol can be calculated by assessing a given CI-A value against the closest corresponding threshold value (in terms of latitude and altitude); if the CI-A value is smaller than the threshold value, then this measurement is flagged as cloud-free; otherwise the measurement is considered as cloud/aerosol influenced.

\subsubsection{Threshold characteristics for CI-A}

The optimal thresholds calculated from the above recipe to capture the seasonal, altitude and latitude dependency of CIA are shown in Fig. 2. In the upper troposphere from $10 \mathrm{~km}$ to $12 \mathrm{~km}$, all threshold profiles vary from approximately 2.0 to 5.0, indicative of the region where the variability of $\mathrm{H}_{2} \mathrm{O}$ will have the largest impact on the CI-A thresholds. For such regions, knowledge of the $\mathrm{H}_{2} \mathrm{O}$ profiles most relevant to the situation considered will always yield improved cloud detection. Since the optimised threshold is effectively an annual average, the threshold values in the troposphere will be determined by the highest $\mathrm{H}_{2} \mathrm{O}$ concentrations in the simulation profiles corresponding to summer conditions. Therefore, if the true atmosphere is drier and this is known, thinner clouds will be detectable. Above the tropopause to $25 \mathrm{~km}$, the

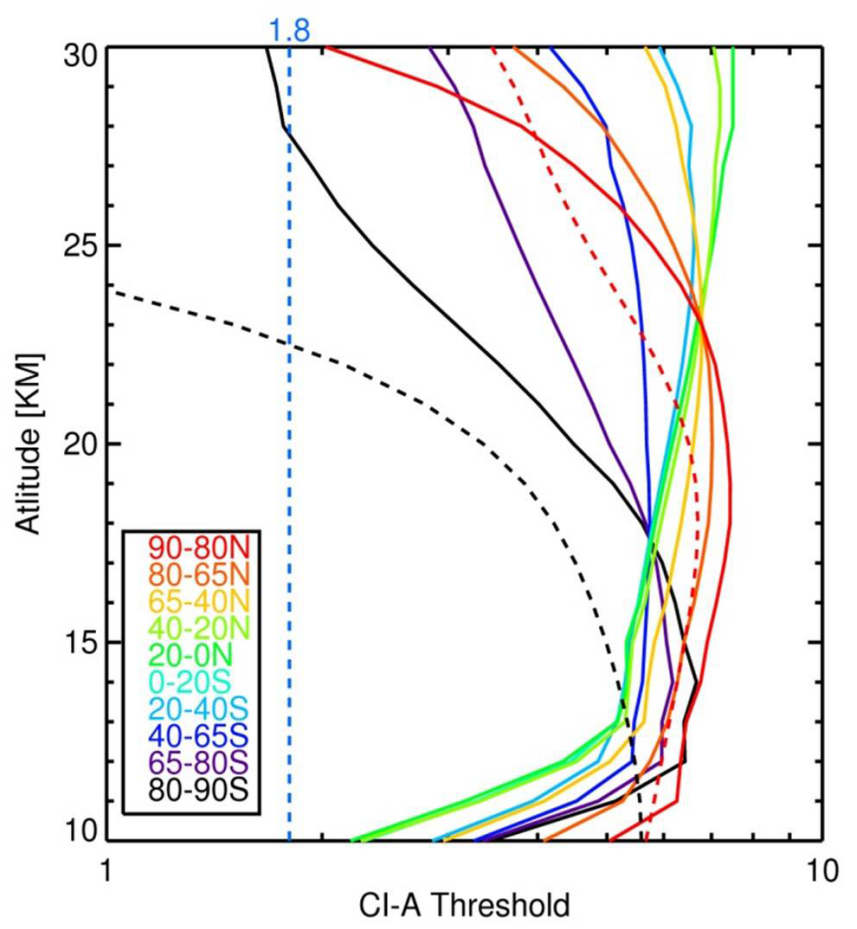

Fig. 2. CI-A threshold profiles for MIPAS from $10 \mathrm{~km}$ to $30 \mathrm{~km}$. Threshold profiles are represented on a latitude grid of $90^{\circ}-80^{\circ}$, $80^{\circ}-65^{\circ}, 65^{\circ}-40^{\circ}, 40^{\circ}-20^{\circ}$ and $20^{\circ}$ to $0^{\circ}$ for Northern and Southern Hemispheres. Profiles are colour-coded for each latitude band (see legend); dotted lines show Arctic (red) and Antarctic (black) thresholds calculated for polar vortex conditions (with enhanced $\mathrm{ClO}$, reduced stratospheric temperature, $\mathrm{HNO}_{3}$ and $\mathrm{O}_{3}$ ). The blue vertical dotted line indicates a fixed threshold of 1.8 .

thresholds remain in the range of 5.0 to 7.0 , representing the particle influenced/clear sky barrier captured by the trace gas variability considered. In the tropics above $25 \mathrm{~km}$, the thresholds remain relatively constant between 5.0 and 7.0, indicating that neither trace gas variability nor the instrument noise has much impact on the thresholds in this region (expected since the signal-to-noise will vary approximately with temperature, which does not vary by large amounts in the tropics). Variations between individual RFM simulations were found to be less than 0.5 in the index profiles (with noise) in the stratosphere in the tropics and of the order of 1.0 to 1.5 in the mid-latitudes.

In contrast, the polar thresholds $\left(90-80^{\circ} \mathrm{N}\right.$ and $90-80^{\circ} \mathrm{S}$ profiles) above $25 \mathrm{~km}$ tend to reach values of 2.0 or less. It is here where the instrument NESR can be comparable to (or lower than) the polar atmospheric radiances, and this threshold behaviour is influenced mainly by the large temperature gradients observed in the polar stratosphere throughout the seasons. During polar winter when the temperatures are at a minimum, MIPAS radiances reduce accordingly, meaning that the instrument noise starts to become dominant and cause the thresholds to reduce. However, this is not the only 
effect, and in the next section, polar stratosphere thresholds are considered explicitly.

\subsubsection{Polar stratosphere thresholds}

Additional threshold profiles were calculated for the Arctic and Antarctic specifically for polar vortex conditions where the simulations included enhanced chlorine monoxide $(\mathrm{ClO})$ with reduced stratospheric temperature, $\mathrm{HNO}_{3}$ and $\mathrm{O}_{3}$ concentrations. It should be noted that no variable $\mathrm{H}_{2} \mathrm{O}$ profiles were included in these calculations since the stratosphere is relatively dry. To ensure the chosen temperatures, $\mathrm{O}_{3}, \mathrm{ClO}$ and $\mathrm{HNO}_{3}$ concentrations were representative of north and south polar vortex conditions, Fig. 3 of Manney et al. (2011) was consulted. For the Arctic, an enhanced layer of $\mathrm{ClO}$ reaching concentrations up to $1.6 \mathrm{ppbv}$ between $15 \mathrm{~km}$ and $25 \mathrm{~km}$ was introduced with reduced stratospheric temperatures to $195 \mathrm{~K}, \mathrm{HNO}_{3}$ concentrations at $4 \mathrm{ppbv}$ and $\mathrm{O}_{3}$ as low as 1 ppmv. For the Antarctic, the $\mathrm{ClO}$ layer was set to concentrations up to $1 \mathrm{ppbv}$, with $\mathrm{HNO}_{3}$ concentrations at 2 ppbv, $\mathrm{O}_{3}$ at $0.5 \mathrm{ppmv}$ and temperature as low as $190 \mathrm{~K}$. The calculated index profiles are displayed in Fig. 2 (dotted lines) and show that, within the polar vortex conditions, the resultant thresholds can reduce severely, particularly above $20 \mathrm{~km}$ and are heavily influenced by reduction in $\mathrm{O}_{3}$ and $\mathrm{HNO}_{3}$ and the steep temperature gradient introduced by the vortex. To demonstrate this large impact of polar temperature variability in further detail, Fig. 3 shows non-vortex index profiles calculated using January and July IG2 profiles for the Arctic and Antarctic from $15 \mathrm{~km}$ to $30 \mathrm{~km}$. The solid lines represent the index profiles for January and July and the dotted lines represent the range of the corresponding $\sigma_{\mathrm{CI}}$ for both Hemispheres. As expected, there are large fluctuations in $\sigma_{\mathrm{CI}}$ from the index profile driven by the steep temperature gradients. In essence, these profiles show a large degree of uncertainty with changes in the thresholds dictated by the varying stratospheric temperatures with season. Therefore, although the use of the annual average polar thresholds will certainly discriminate many PSCs, and particularly thick PSCs, caution should be exercised in situations of strong stratospheric polar ozone depletion. For these cases, individual analyses are recommended according to the specific atmospheric conditions prevailing in the study period.

\subsubsection{Threshold detection limits}

To understand the extinction detection range encompassed by the thresholds, a set of CI-A microwindow simulations were performed using profiles from the IG2 database with representative background aerosol extinction profiles for each IG2 latitude band for all seasons and on a $1 \mathrm{~km}$ vertical grid. A "cloud" was added to each simulation by perturbing the extinction profile from $1 \times 10^{-2} \mathrm{~km}^{-1}$ to $1 \times 10^{-6} \mathrm{~km}^{-1}$ between the altitudes of $6 \mathrm{~km}$ and $30 \mathrm{~km}$ in $1 \mathrm{~km}$ steps. Figure 4 provides an example of the CI-A and extinction relationship,
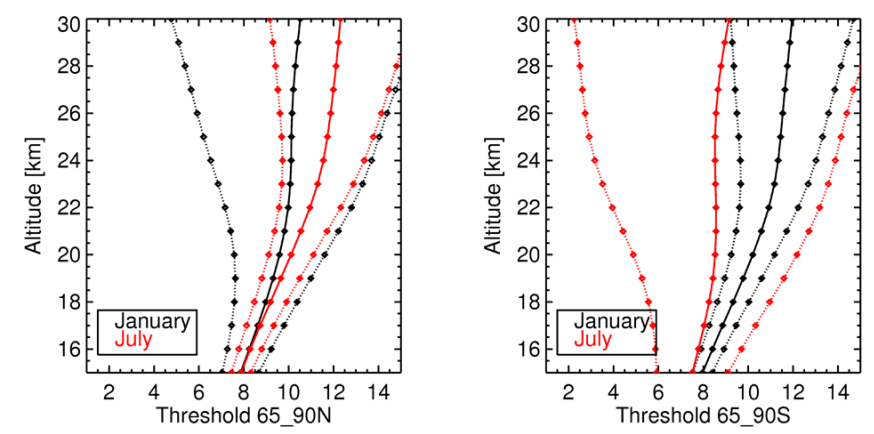

Fig. 3. Variation of Arctic and Antarctic index and $\sigma_{\mathrm{CI}}$ profiles in January and July. Solid lines represent the calculated index profile and the dotted lines represent the range in $\sigma_{\mathrm{CI}}$. The large variation in $\sigma_{\mathrm{CI}}$ reflects the impact of the change in stratospheric temperatures throughout the poles for both seasons.

showing the variation of extinction as a function of altitude and CI-A for the latitude band $65^{\circ} \mathrm{N}$ to $20^{\circ} \mathrm{N}$ in January. CIA values between 2.0 and 4.0 generally correspond to extinctions at $12 \mu \mathrm{m}$ between $5 \times 10^{-3} \mathrm{~km}^{-1}$ and $1 \times 10^{-3} \mathrm{~km}^{-1}$, respectively, and values from 4.0 to 6.0 correspond to extinction ranges from $1 \times 10^{-3} \mathrm{~km}^{-1}$ to $1 \times 10^{-4} \mathrm{~km}^{-1}$, respectively. For CI-A values falling below 2.0, the extinction detectable is close to $1 \times 10^{-2} \mathrm{~km}^{-1}$. This range of extinction values that are detectable in the $12 \mu \mathrm{m}$ spectral region indicates that optically thick cirrus clouds as well as thick aerosol layers (such as those from volcanoes or wildfire burning events) should be discernible with the optimised threshold profiles derived here. Above $13 \mathrm{~km}$, particles can be detected up to CI-A values of 5.0, and in the stratosphere it is possible to detect particles in some regions with CI-A up to 6.0 or higher, giving detection limits above $13 \mathrm{~km}$ of $1 \times 10^{-4} \mathrm{~km}^{-1}$ and down to $1 \times 10^{-5} \mathrm{~km}^{-1}$ in parts of the stratosphere.

\section{Cloud detection results}

Given that the detection system described in the previous section takes into account the seasonal and latitude dependency of the radiance changes in the cloud microwindows, it should effectively capture short- and long-term cloud behaviour as well as specific events likely to perturb the particulate concentrations of the atmosphere. All detection results shown in the following sections will be demonstrated by the Cloud and Aerosol Top Height (CATH) where the cloud or aerosol layer height is inferred directly from the reprocessed Level $1 \mathrm{~b}$ emission spectrum measurements as obtained from the ESA operational IPF5.0 (version 5.0) processor. MIPAS tangent height measurements provided with each L1B spectral radiance profile are based on calculated engineering altitudes. Prior to March 2004 when MIPAS was in its FR mode, an elevation pointing error was discovered between the North and South Poles (Kiefer et al., 2007), but this has 


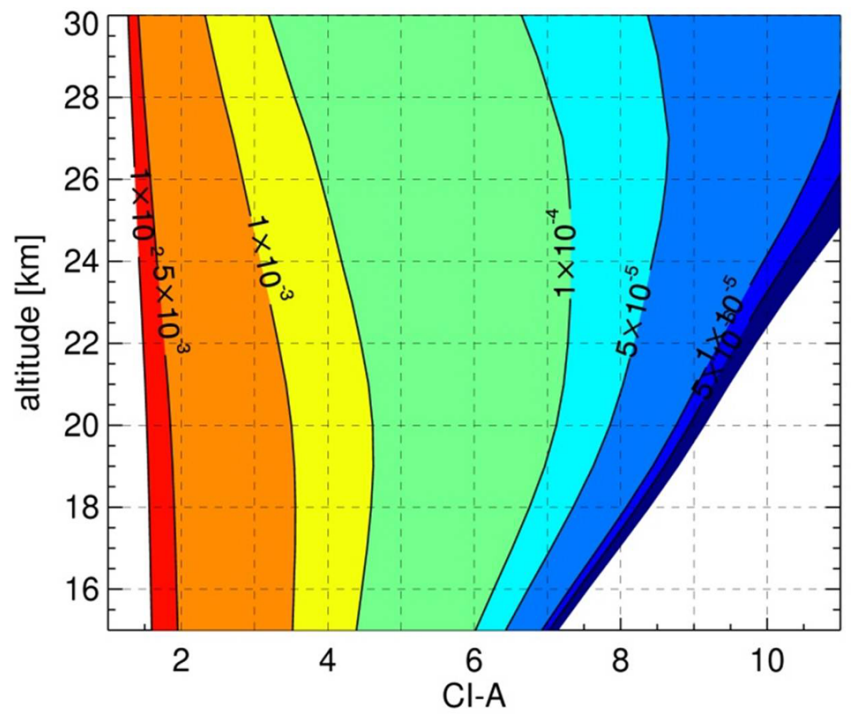

Fig. 4. Variation of equivalent $12 \mu \mathrm{m}$ extinction, for $65^{\circ} \mathrm{N}$ to $20^{\circ} \mathrm{N}$ in January, as a function of altitude and CI-A. Different colours correspond to the extinction limits between $1 \times 10^{-2} \mathrm{~km}^{-1}$ and $1 \times 10^{-6} \mathrm{~km}^{-1}$.

been corrected to $0.5 \mathrm{~km}$ accuracy in Version 5.0. All data shown in this paper were obtained in the OR mode that did not suffer from this particular bias. It has been found that the engineering altitudes in the OR L1b dataset show a $0.3 \mathrm{~km}$ low bias compared to retrieved MIPAS altitudes (M. Kiefer, personal communication, 2011).

The CATH is calculated by assessment of each cloud index profile (derived directly from MIPAS Level $1 \mathrm{~b}$ spectral profiles) against the corresponding latitudinal and altitude thresholds. The tangent altitude at which the threshold ceases to be larger than the CI-A value is declared as the CATH and this is the tangent altitude at which cloud or aerosol particles are detected within the MIPAS FOV. It should be noted that due to the $3 \mathrm{~km}$ MIPAS FOV, the assignment of cloud top altitude can be conservatively in error by $\pm 1.5 \mathrm{~km}$; the errors are in principle asymmetric with MIPAS expected to show CATH which are higher than reality. Simulations by Höpfner et al. (2009) show biases of 0.5 to $1.0 \mathrm{~km}$ introduced for cloud layers which fill the tangent layer. We also compute the occurrence frequency (OF) for CATH defined as the ratio of cloud and aerosol top heights to total points found within a defined altitude range.

In the following sections the CATH datasets are used to investigate specific atmospheric events to assess the efficiency and success of the detection method. Section 6.1 shows the results of a statistical comparison of MIPAS with HIRDLS and CALIOP cloud information for selected periods in 2007 and 2008. The detection thresholds are then applied to two localised events which illustrate the significance of the new detection thresholds: one is the Australian "Black Saturday" bushfires of February 2009 (Sect. 6.2) with comparison to measurements taken from the CALIOP lidar, and the second is the detection of Mount Kasatochi volcanic eruptions of August 2008 in Sect. 6.3.

\subsection{Inter-comparison of MIPAS CATH and OF with HIRDLS and CALIOP}

The periods of data chosen for a statistical comparison of MIPAS and HIRDLS are June-July-August (JJA) 2007 and December-January-February (DJF) 2007/2008. During this period, all MIPAS measurements were in OR mode and there were no major volcanic eruptions meaning background cloud fields and the seasonal variation of clouds can be analysed. HIRDLS cloud data are selected for these periods by fulfilling the data selection criteria, as described in Sect. 3.1, from which the HIRDLS CATH is extracted by searching for the topmost altitude at which the cloud and aerosol flags are nonzero in each HIRDLS profiles measurement. To ensure consistency in the inter-comparisons (as MIPAS and HIRDLS cover a different range of heights in each profile measurement), the CATH (and OF) comparisons are performed only in the altitude range where MIPAS and HIRDLS data exist. In this case, the inter-comparisons are performed only between $12 \mathrm{~km}$ and $20 \mathrm{~km}$, for both day and night conditions, over latitudes between $50^{\circ} \mathrm{N}$ and $50^{\circ} \mathrm{S}$.

Figure 5 shows maps of mean CATH for JJA 2007 and DJF 2008 from MIPAS and HIRDLS between $50^{\circ} \mathrm{N}$ and $50^{\circ} \mathrm{S}$ and $12 \mathrm{~km}$ to $20 \mathrm{~km}$ gridded onto a regular $5^{\circ}$ latitude and $10^{\circ}$ longitude grid. In JJA, both MIPAS and HIRDLS detect regions of high clouds up to $17.5 \mathrm{~km}$ over the West Pacific Ocean, equatorial Africa and the North American and Asian Monsoon regions. In the mid-latitudes, both instruments detect cloud bands between $12 \mathrm{~km}$ and $14 \mathrm{~km}$ and are in relatively good agreement through the tropical/mid-latitude transition regions. In DJF, the shift in the cloud pattern following the movement of the inter-tropical convergence zone (ITCZ) is evident in both MIPAS and HIRDLS, with the highest clouds located within the $20^{\circ} \mathrm{N}$ and $20^{\circ} \mathrm{S}$ band over the West Pacific Ocean, equatorial America, Africa and Indonesia. The MIPAS detection locates clouds at $18 \mathrm{~km}$ over the east Pacific Ocean in comparison to HIRDLS, which shows clouds closer to $17 \mathrm{~km}$. The most striking features to notice in both seasons are the strong agreement in the distribution of clouds in the tropics and sub-tropics with regions of more persistent cloud systems, such as the Asian Monsoon in JJA and the Pacific cold trap region in DJF, well identified in both datasets.

To compare the occurrence of cloud and aerosol particles in both instruments over the period of interest, the mean OF over a $12 \mathrm{~km}$ to $20 \mathrm{~km}$ column, gridded onto a $5^{\circ}$ latitude and $10^{\circ}$ longitude grid, is analysed. Figure 6 shows the mean OF for MIPAS and HIRDLS for JJA 2007 and DJF 2008 between $50^{\circ} \mathrm{N}$ and $50^{\circ} \mathrm{S}$. Bands of mean OF between $5 \%$ and $10 \%$ flowing through the mid-latitudes are evident in both datasets in both seasons analysed. In the tropics, the mean OF is close 

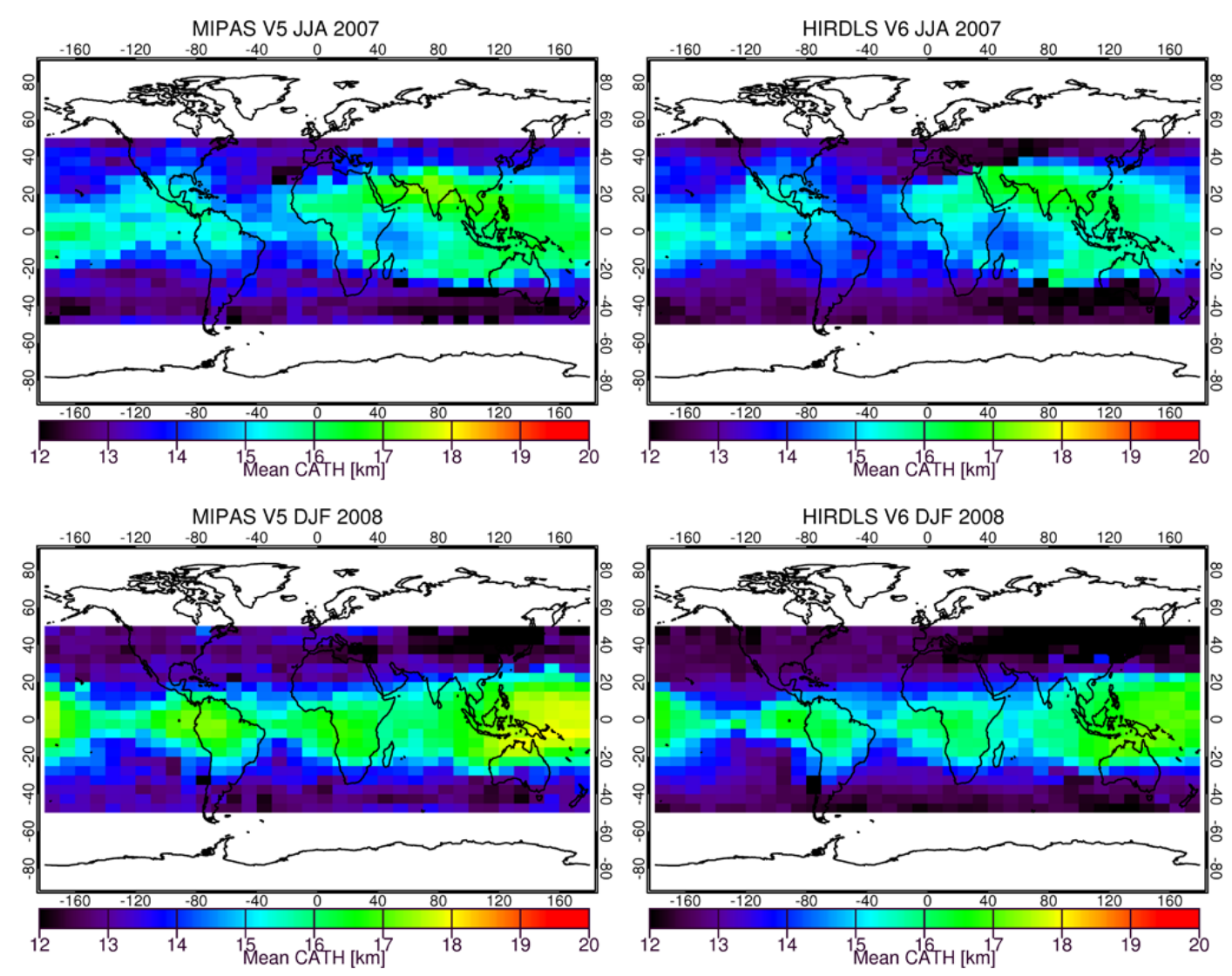

Fig. 5. MIPAS and HIRDLS mean CATH for JJA 2007 and DJF 2007/2008 in the range of $12 \mathrm{~km}$ to $20 \mathrm{~km}$ between $50^{\circ} \mathrm{N}$ and $50^{\circ} \mathrm{S}$ on a $5^{\circ}$ latitude and $10^{\circ}$ longitude grid. Top left: MIPAS JJA 2007, top right: HIRDLS JJA 2007; bottom left: MIPAS DJF 2008 and bottom right HIRDLS DJF 2008.

to $45 \%$ in both seasons. However, the greatest OF values of up to $60 \%$ coincide with the regions of highest clouds localised over the North American and Asian Monsoon regions in JJA, and over the tropical landmasses and tropical Pacific Ocean in DJF. Overall, the occurrence patterns are in excellent agreement although MIPAS cloud distributions tend to show a more widespread pattern with HIRDLS demonstrating a more compact distribution. This is in line with the fact that the HIRDLS instrument measured profiles on a denser network (approximately $110 \mathrm{~km}$ spacing in the N-S direction) compared to that of MIPAS which were spaced closer to $440 \mathrm{~km}$. The higher vertical resolution of HIRDLS also results in smaller horizontal extents of the tangent layers compared to MIPAS, which is also likely an effect.

To further quantify the differences between the mean CATH from MIPAS and HIRDLS and to verify the range of CATH observed in MIPAS, comparisons of the JJA 2007 and DJF 2008 CATH are made to those inferred from CALIOP measurements. In this analysis, CATH are extracted from CALIOP level 2 cloud/aerosol layer $5 \mathrm{~km}$ (version 3.01) data products where the CALIOP CATH selection of feature (cloud or aerosol) height is based on determining the highest cloud or aerosol layer boundary in each measurement. The altitude (reported in $\mathrm{km}$ ) at which this occurs is simply the cloud/aerosol height as measured by CALIOP.

Figure 7 shows normalised distributions of gridded mean CATH for JJA 2007 and DJF 2008 binned into $0.5 \mathrm{~km}$ grid boxes between $12 \mathrm{~km}$ and $20 \mathrm{~km}$ for MIPAS, HIRDLS and CALIOP. In both seasons the shapes of the distributions are similar for all instruments, showing two peaks indicating their sensitivity to upper tropospheric clouds as well as optically thinner cirrus clouds close to the tropopause. The overall distribution of CALIOP CATH has a similar shape to both MIPAS and HIRDLS; however, the distributions are more consistent with the HIRDLS CATH data, with MIPAS showing an offset up to $+1 \mathrm{~km}$ against CALIOP. A consistent feature in both seasons is that MIPAS cloud altitudes appear to be, on average, approximately $0.75 \mathrm{~km}$ higher than both HIRDLS and CALIOP. This bias shows consistency with the theoretical bias of $0.5-1 \mathrm{~km}$ calculated by Höpfner et al. (2009) for scenarios when a cloud is detected as soon as it appears and fills a tangent layer the MIPAS FOV.

Recently Version 6 HIRDLS cloud top data have been compared to $8 \mathrm{yr}$ (1997-2005) of HALOE data in the HIRDLS data quality document (Gille et al., 2011). The HALOE cloud top heights are higher by up to $1 \mathrm{~km}$ compared 

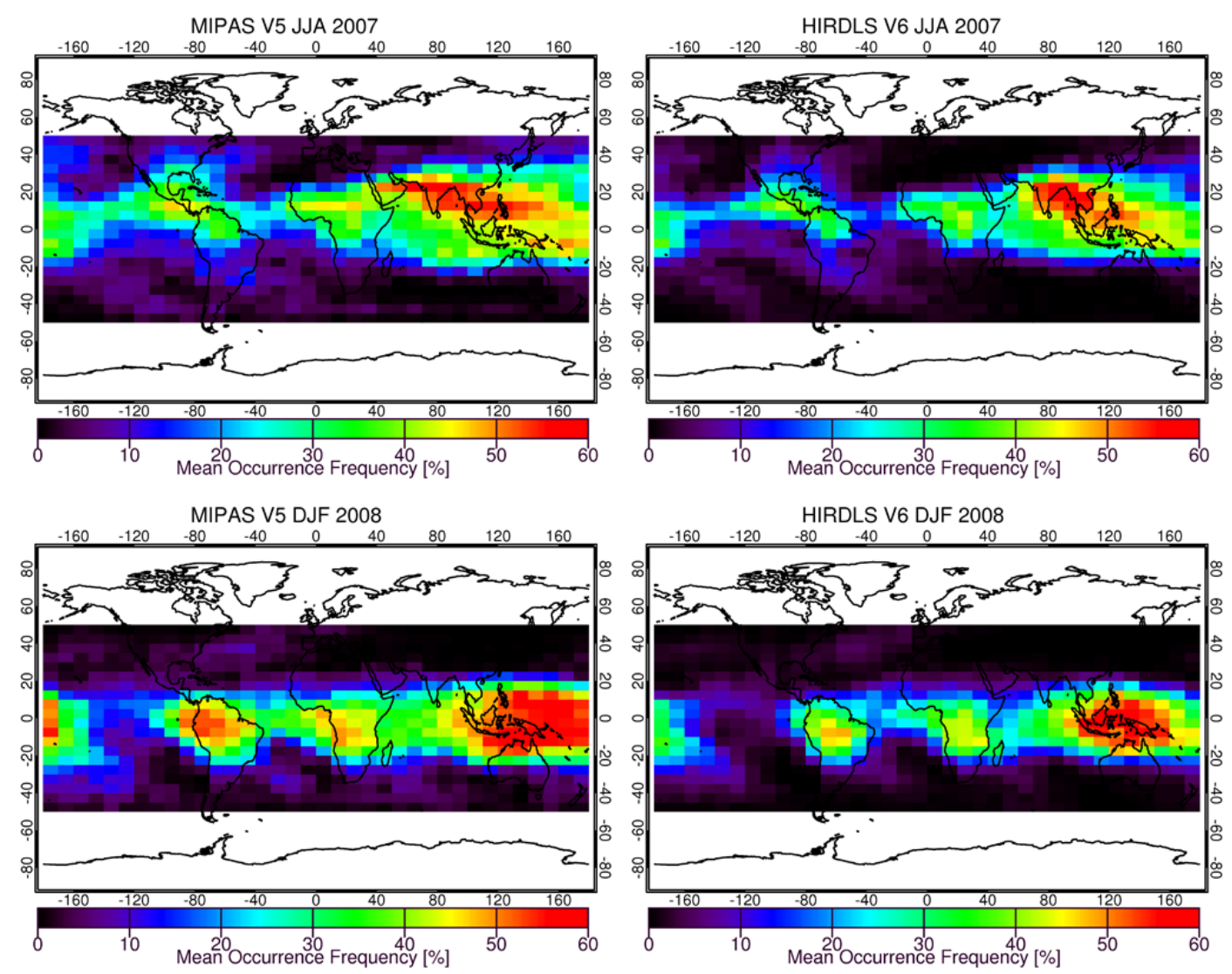

Fig. 6. MIPAS and HIRDLS mean OF for JJA 2007 and DJF 2007/2008 in the range of $12 \mathrm{~km}$ to $20 \mathrm{~km}$ (binned on a $1 \mathrm{~km}$ vertical grid) between $50^{\circ} \mathrm{N}$ and $50^{\circ} \mathrm{S}$ on a $5^{\circ}$ latitude and $10^{\circ}$ longitude grid. Top left: MIPAS JJA 2007, top right: HIRDLS JJA 2007; bottom left: MIPAS DJF 2008 and bottom right HIRDLS DJF 2008.
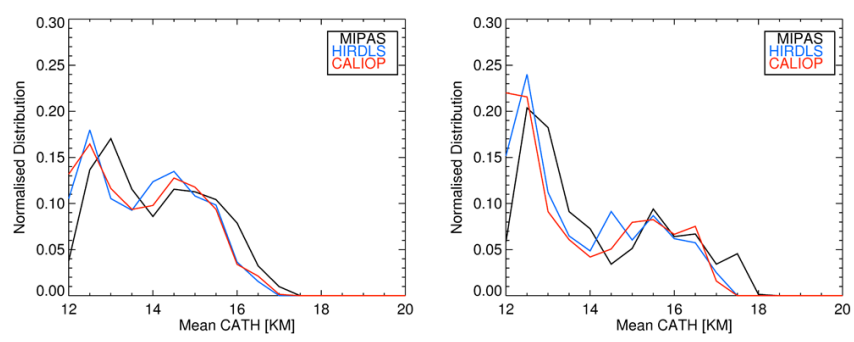

Fig. 7. Normalised frequency distributions of MIPAS and HIRDLS mean gridded CATH for JJA 2007 and DJF 2007/2008 for data from $12 \mathrm{~km}$ to $20 \mathrm{~km}$, between $50^{\circ} \mathrm{N}$ to $50^{\circ} \mathrm{S}$ on a $5^{\circ}$ latitude and $10^{\circ}$ longitude grid compared to corresponding gridded mean CALIOP CATH.

to HIRDLS data in the tropics and mid-latitudes, a bias similar to the MIPAS-HIRDLS comparisons. Overall, it therefore seems that limb sounders give a very consistent picture of cloud distributions throughout the tropics and mid-latitudes with a strong agreement to CALIOP.

\subsection{Black Saturday bushfires as observed by MIPAS and CALIOP}

The Black Saturday bushfires were an unprecedented occurrence in which approximately $4500 \mathrm{~km}^{2}$ of land burned uncontrollably in Victoria, Australia from the 7 February to the 14 March 2009 (CSIRO, 2011). Recently, Pumphrey et al. (2011) investigated enhancements of CO and other combustion by-products, including hydrogen cyanide ( $\mathrm{HCN})$ and ethanenitrile $\left(\mathrm{CH}_{3} \mathrm{CN}\right)$, within the plumes using MLS version 2.2 retrieved profiles for February and March 2009. They observed CO enhancements to the north of New Zealand at $100 \mathrm{hPa}$, and anomalously high concentrations reaching up to $46 \mathrm{hPa}$ (close to $20 \mathrm{~km}$ ) several days after the fires began, with $\mathrm{CO}$ concentrations reaching levels 3 times higher than background concentrations. Trajectory analyses showed that these polluted air masses originated over Victoria and traversed across southeast Australia after becoming trapped in an anti-cyclonic system to the north of New Zealand.

Work done by Siddaway and Petelina (2011) showed the transport of smoke plumes by detection of limb solar-scattered radiance enhancements from the OSIRIS 


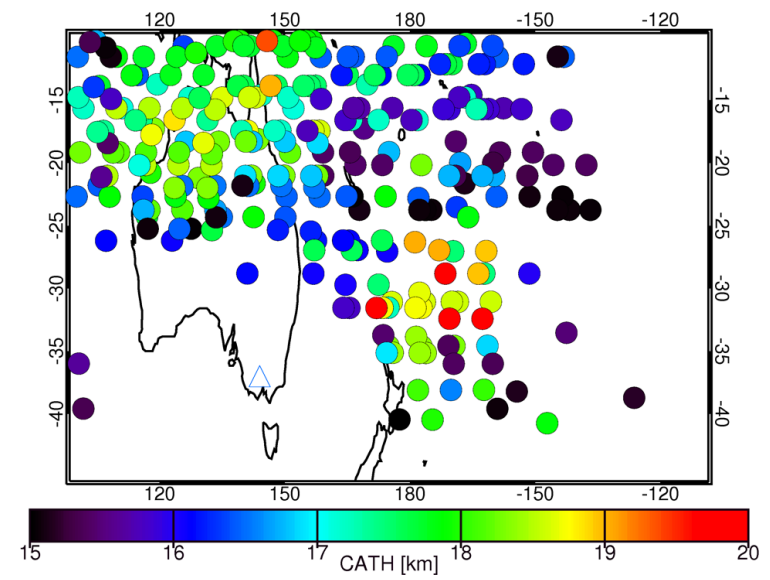

Fig. 8. Map of MIPAS CATH between $15 \mathrm{~km}$ and $20 \mathrm{~km}$ for 7 February to 16 February 2009 over Australia and New Zealand. The blue triangle indicates the position of Victoria (located at $38^{\circ} \mathrm{S}$, $143^{\circ} \mathrm{E}$ ) where the Black Saturday bushfires originated.

instrument. The authors showed that the main plume travelled eastwards to the north of New Zealand from the 11 February, reaching altitudes between $16 \mathrm{~km}$ and $18 \mathrm{~km}$. The location of the smoke plume matched the enhanced pollutants measured by MLS, with the primary smoke plume near-stationary over northeast of New Zealand. In the following weeks, the plume was traceable across the Southern Hemisphere for at least 6 weeks with some advection up to $21 \mathrm{~km}$.

Figure 8 shows a map of CATH in the $15 \mathrm{~km}$ to $20 \mathrm{~km}$ layer for the Black Saturday bushfires, with the corresponding CIA values shown in Fig. 9. A region of elevated CATH, from $18 \mathrm{~km}$ to $20 \mathrm{~km}$, can be observed between $25^{\circ} \mathrm{S}$ and $35^{\circ} \mathrm{S}$ and $170^{\circ} \mathrm{E}$ and $170^{\circ} \mathrm{W}$, with the first indication of CATH reaching $18 \mathrm{~km}$ on 9 February. Analysis of potential temperatures extracted from the National Centers for Environmental Prediction (NCEP) reanalysis fields (Kalnay et al., 1996) using the Hybrid Single Particle Lagrangian Integrated Trajectory Model (Draxler and Rolph, 2012) indicates that these elevated CATH occur at potential temperatures greater than $380 \mathrm{~K}$ and are therefore stratospheric. Figure 9 shows a region of lowered CI-A values at latitudes south of $28^{\circ} \mathrm{S}$; MIPAS observations in other years show that CI-A values are typically greater than 8.0 in this region. Analysis of the CI-A values corresponding to the MIPAS CATH within the bushfire plumes shows that many of the CI-A values lie in the 4.0 to 6.0 range. In terms of extinctions, this corresponds to aerosol material of approximately $7 \times 10^{-4} \mathrm{~km}^{-1}$ to $1 \times 10^{-5} \mathrm{~km}^{-1}$, respectively. Given this range of CI-A values, the optimised threshold profiles perform well and capture the additional aerosol injection efficiently. Using the operational CI-A threshold of 1.8 would in fact completely fail to detect the MIPAS measurements in the bushfire outflow region as it is designed primarily to detect optically thick cirrus clouds. Using a fixed threshold of 4.0 would improve on

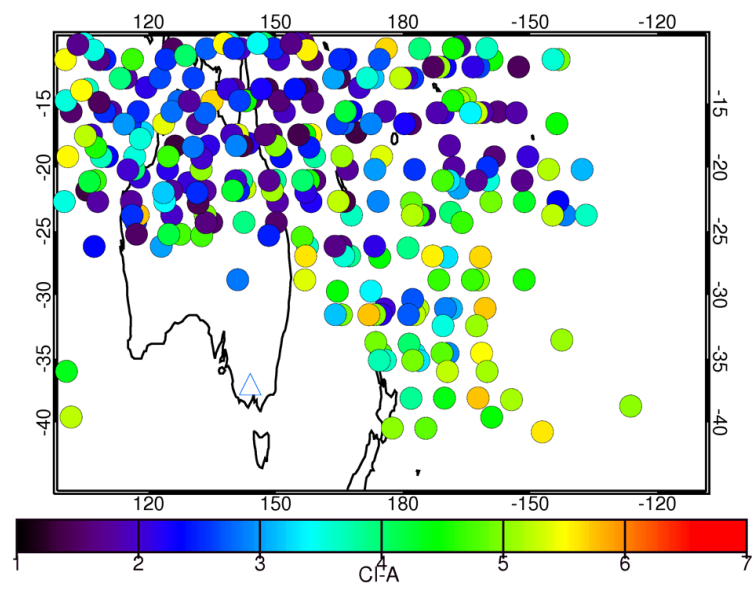

Fig. 9. Map of MIPAS CI-A between $15 \mathrm{~km}$ and $20 \mathrm{~km}$ for 7 February to 16 February 2009 over Australia and New Zealand. The blue triangle indicates the position of Victoria (located at $38^{\circ} \mathrm{S}, 143^{\circ} \mathrm{E}$ ) where the Black Saturday bushfires originated.

the plume detection compared to 1.8 but would still in fact miss much of the wider plume reaching the UTLS. Thus, in the case of detecting wildfire influence in the UTLS, the improved detection thresholds offer a unique sensitivity that cannot be achieved with the fixed threshold process.

To provide some inter-comparison for the range of CATH captured by MIPAS during the bushfires, MIPAS and CALIOP CATH nighttime data are compared for 7 February to 16 February 2009 between $10^{\circ} \mathrm{S}$ and $50^{\circ} \mathrm{S}$. Figure 10 shows the captured CATH between $15 \mathrm{~km}$ and $20 \mathrm{~km}$. It should be noted that the MIPAS measurements are obtained approximately $3 \mathrm{~h}$ before the CALIOP measurements and thus some differences are expected. The general pattern of CATH distributions show that clouds occur over Northern Australia within the tropical belt at altitudes close to $18 \mathrm{~km}$ as seen by CALIOP and MIPAS. The Pacific Ocean region to the east of Australia generally shows lower clouds (close to $15 \mathrm{~km} / 16 \mathrm{~km}$ ) or virtually no tropopause clouds in both MIPAS and CALIOP. The key features observed in both datasets are the position of the plume located close to $180^{\circ}$ longitude and elevated CATH reaching as high as $20 \mathrm{~km}$ in both CALIOP and MIPAS.

The MIPAS detection has captured the spatial extent and scale of the plume outflow well and the improved detection thresholds show a reasonable sensitivity to the cloud and aerosol material resulting from the bushfire plumes. No CALIOP data were available for the remainder of February. However, analysis of MIPAS CATH for this period captures the gradual movement of plume northwest towards Australia from 16 February, eventually moving westwards across Australia and over the Indian Ocean by 28 February 2009. These positions of the bushfire aerosol plume measured in MIPAS during February are in very good agreement with smoke plume detected with the OSIRIS instrument (Siddaway and Petelina, 2011). 


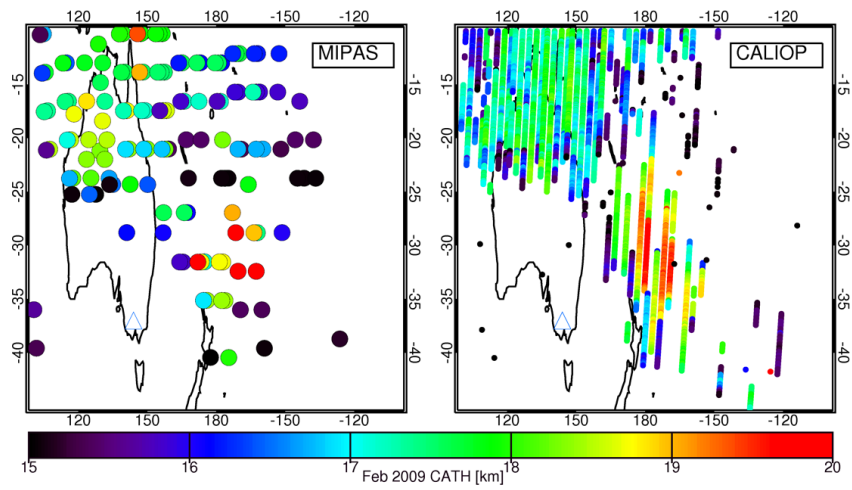

Fig. 10. Comparison of MIPAS and CALIOP CATH (nighttime data for both datasets) from 7 February to 16 February 2009 over Australia and New Zealand. The blue triangle indicates the position of Victoria (located at $38^{\circ} \mathrm{S}, 143^{\circ} \mathrm{E}$ ) where the Black Saturday bushfires originated.

\subsection{MIPAS detection of Mount Kasatochi Aerosols}

From 7 to 8 August 2008, the Mount Kasatochi volcano, situated on the Alaskan Aleutian Islands at $52^{\circ} \mathrm{N}, 175^{\circ} \mathrm{W}$, began erupting with 3 major explosive events releasing pyroclast, ash and $\mathrm{SO}_{2}$ reaching altitudes up to $18 \mathrm{~km}$ (Waythomas et al., 2010). Prata et al. (2010) exploited $\mathrm{SO}_{2}$ features in Atmospheric Infrared Sounder (AIRS) spectral measurements to study the partial columns of $\mathrm{SO}_{2}$, based on the $1363 \mathrm{~cm}^{-1}$ and $2500 \mathrm{~cm}^{-1}$ spectral regions. Using these retrievals in conjunction with ash detection from the $800 \mathrm{~cm}^{-1}-1200 \mathrm{~cm}^{-1}$ spectral range, it was found that Kasatochi ash and UTLS $\mathrm{SO}_{2}$ appeared to disperse from the volcano simultaneously, travelling together towards North America for the first few days after the eruption. Overall, they estimated an $\mathrm{SO}_{2}$ mass loading of approximately $1.7 \mathrm{Tg}$ was released into the atmosphere from Kasatochi alone. The evolution and transport of the Kasatochi plume stratospheric layer has been well documented with measurements from limb and nadir sounders. Bourassa et al. (2010) used $750 \mathrm{~nm}$ extinction retrievals from OSIRIS measurements to investigate the stratospheric aerosol formation following the Kasatochi eruptions. Using zonally-averaged aerosols extinctions from March 2008 (pre-eruption) to May 2009, they observed the development of a stable stratospheric aerosol layer from $15 \mathrm{~km}$ to $21 \mathrm{~km}$ from 4 weeks after the eruption over the mid- and high latitudes, with the stratospheric aerosol layer persisting until March 2009. Sioris et al. (2010) similarly observed stratospheric aerosol enhancements over the same timescales using NIR extinction retrievals from the ACE-FTS instrument in which the aerosol enhancements were observed up to $19 \mathrm{~km}$ in the Northern Hemisphere.

The addition of Kasatochi volcanic material into the UTLS produced large radiance enhancements and strong volcanic signatures in MIPAS spectra. Figure 11 shows Northern Hemispheric MIPAS CATH observed between $60^{\circ} \mathrm{N}$ and

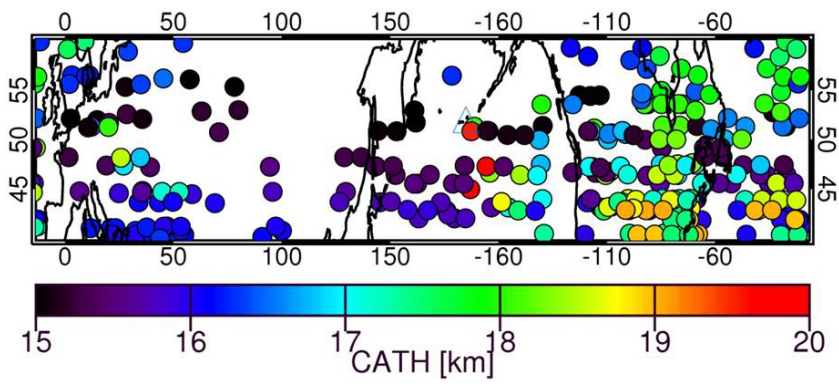

Fig. 11. MIPAS CATH in the range of $15 \mathrm{~km}$ to $20 \mathrm{~km}$ between $60^{\circ} \mathrm{N}$ and $40^{\circ} \mathrm{N}$ from 7 August (first Kasatochi eruption) to $31 \mathrm{Au}$ gust 2008. Location of Mount Kasatochi at $52^{\circ} \mathrm{N}, 175^{\circ} \mathrm{W}$ is indicated by the blue triangle.

$40^{\circ} \mathrm{N}$ from 7 August to 31 August 2008. Evidence of elevated CATH are observed directly over the source region at $52^{\circ} \mathrm{N}, 175^{\circ} \mathrm{W}$, with Kasatochi influence initially observed up to $20 \mathrm{~km}$. CATH between $17 \mathrm{~km}$ and $19 \mathrm{~km}$ are observed extending over North America, passing across the North Atlantic at latitudes close to $45^{\circ} \mathrm{N}$. This range of heights for the Kasatochi plumes observed in MIPAS are similar to those in the ACE-FTS and OSIRIS measurements. Examination of CALIOP lidar images for 10 August 2008 similarly show layers of volcanic material between $16 \mathrm{~km}$ and $19 \mathrm{~km}$ over the Kasatochi region that gradually move across North America by 20 August 2008. Such transport across the Northern Hemisphere on the consecutive days analysed shows very strong agreement with $\mathrm{SO}_{2}$, ash and aerosol detection from the Infrared Atmospheric Sounding Interferometer (IASI), AIRS and the Ozone Monitoring Experiment (OMI), as reported in the studies of Karagulian et al. (2010) and Kristiansen et al. (2010).

To quantify the efficiency of the optimised thresholds for the detection of volcanic plume material, the Kasatochi CIA values for 7 August to 31 August 2008 in the $15 \mathrm{~km}$ to $20 \mathrm{~km}$ range are shown in Fig. 12. The CI-A values largely vary between 4.0 and 6.0 within the main transport region of Kasatochi across North America; this CI-A range is fully encompassed with the optimised thresholds and therefore the plume influenced MIPAS measurements are captured sufficiently well. In comparison to the fixed threshold method, a CI-A threshold value of 2.0 or 4.0 would not succeed in identifying such material accurately and therefore result in a rather sporadic detection of volcanic intrusions from MIPAS.

To observe the evolution of the aerosol layer from MIPAS, Fig. 13 shows the frequency distributions of MIPAS CATH for selected months from February 2008 to February 2009; this selection contains a pre-eruption phase and up to 7 months after the eruptions. The difference between February 2008 and August 2008 is marked by a distinctive shift in the peak CATH of approximately $3 \mathrm{~km}$ between the two months, with a general enhancement in the $11 \mathrm{~km}$ to $18 \mathrm{~km}$ range in August 2008; highest values of CATH in 


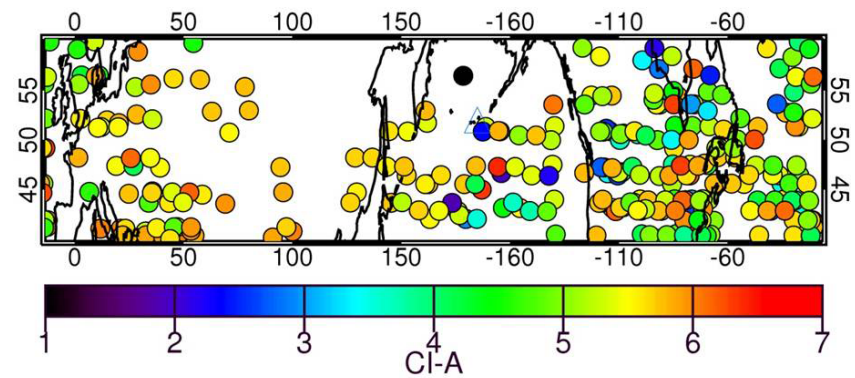

Fig. 12. Map of MIPAS CI-A corresponding to CATH in the range of $15 \mathrm{~km}$ to $20 \mathrm{~km}$ between $60^{\circ} \mathrm{N}$ and $40^{\circ} \mathrm{N}$ from 7 August (first Kasatochi eruption) to 31 August 2008. Location of Mount Kasatochi at $52^{\circ} \mathrm{N}, 175^{\circ} \mathrm{W}$ is indicated by the blue triangle.

February 2008 were typically $14 \mathrm{~km}$. By September 2008, the CATH data shows a distinctively broader pattern spread over the $12 \mathrm{~km}$ to $19 \mathrm{~km}$ range initiated by the increase in aerosol as reported by Bourassa et al. (2010) and Sioris et al. (2010). In particular, the growth in the $15 \mathrm{~km}$ to $19 \mathrm{~km}$ distribution during September 2008 and October 2008 is likely to be due to the growth of stratospheric aerosol over a few weeks, as reported by Sioris et al. (2010). By October 2008, the distribution becomes peaked at $15 \mathrm{~km}$, a difference of $5 \mathrm{~km}$ compared to February 2008. As December 2008 is reached, the change in the CATH distribution suggests a return to the normal situation is beginning with the distribution peak shifting to $13 \mathrm{~km}$. By February 2009, the distribution appears to have become clearer and becomes closer to that observed in the pre-eruption phase, indicating that the Kasatochi aerosol influence no longer exists in the Northern Hemisphere region. In this case the CATH indicator with the improved thresholds has proved an excellent demonstration of the MIPAS capability to detect weak aerosol intrusions into the stratosphere, comparable with the measurements of systems such as OSIRIS.

\section{Conclusions}

In this study, improved threshold profiles for the detection of clouds from the MIPAS instrument were derived specifically to maximise the identification of cloud and aerosol particles throughout the UTLS. Within this region, the method allows for statistical evaluation of cloud top occurrence frequencies, monitoring of CATH, detection of individual particle injection events, and tracking of plumes and dispersing aerosol layers. Consequently, a second purpose fulfilled by this scheme is to separate cloud- and aerosol-influenced spectra from clear-sky spectra in an independent, efficient and computationally fast manner, allowing cloud and aerosols properties to be probed in more detailed and computer-intensive retrieval schemes. This is a primary use of the method in the MIPclouds processor (Spang et al., 2012) and for this reason

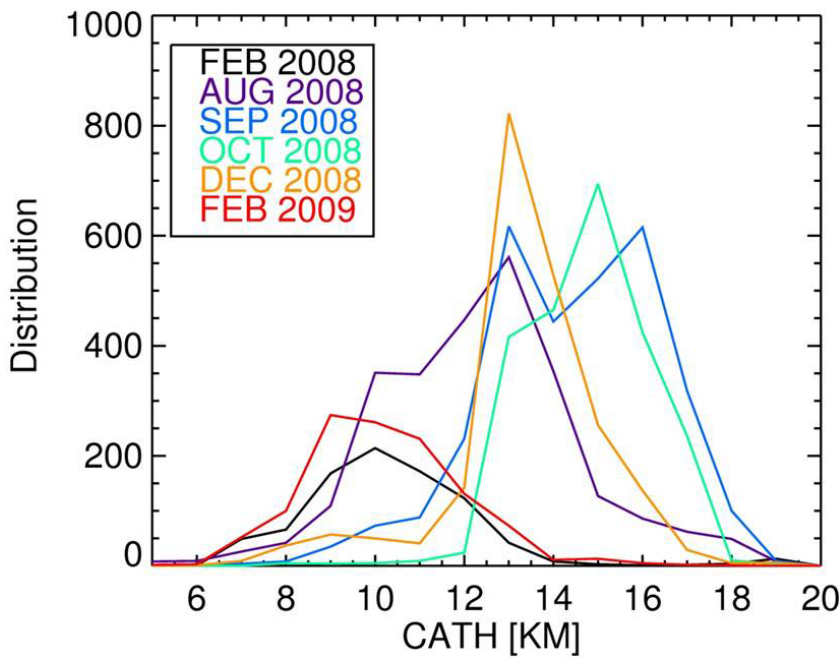

Fig. 13. Frequency distribution of all MIPAS CATH from $60^{\circ} \mathrm{N}$ to $50^{\circ} \mathrm{N}$ for the selected months of February 2008 (pre-Kasatochi), August 2008 (during Kasatochi eruptions) to the post-Kasatochi eruption period of October 2008, December 2008 and February 2009.

it is also suitable for the MIPAS operational processor. In addition, the results of the study indicate considerable value would be obtained by implementing retrievals of aerosol extinction into MIPAS processors.

The variability of the calculated threshold profiles over the globe are indicative of the radiance changes in the $12 \mu \mathrm{m}$ spectral region due to the influence of both atmospheric trace gas variations and instrumental noise effects. In tropical and mid-latitude conditions, the optimised thresholds are quite reflective of conditions over the year so that, although conservative, seasonal variations are small. CI-A thresholds allow detection of particles up to values of 5.0 above $13 \mathrm{~km}$ with some regions allowing detection up to values of 7.0. At $10 \mathrm{~km}$, i.e. in the troposphere, detection is more limited in the tropics due to high $\mathrm{H}_{2} \mathrm{O}$ concentrations, but particle detection in the polar troposphere is much more sensitive (thresholds of 4.0 or higher).

The polar stratospheric thresholds show a larger degree of uncertainty over the changing seasons, meaning the polar regions would be better treated with a different approach in which time and atmospheric composition dependency are considered. Certainly, caution should be exercised in interpreting detection of PSCs when atmospheric chemical composition is strongly perturbed and temperatures are low.

The application of the tropical and mid-latitude thresholds to a statistical cloud comparison showed that large-scale features and general cloud distributions (as represented by cloud occurrence frequencies) observed by MIPAS and HIRDLS are in excellent agreement with MIPAS tending to show marginally broader distributions. Over the $12 \mathrm{~km}$ to $20 \mathrm{~km}$ range, MIPAS CATH are up to $0.5-1 \mathrm{~km}$ higher than those 
detected by HIRDLS and CALIOP, and the likely cause of this bias is due to the effect of vertical oversampling within the MIPAS FOV.

The detection of the Black Saturday and Mount Kasatochi plumes have demonstrated that the improved thresholds can be used to track fire injections and volcanic plumes into the lower stratospheric and across the globe on timescales ranging from days to months. The range of CI-A values found to correspond to these events indicate that the addition of such particles into the UTLS with extinctions values close to $1 \times 10^{-5} \mathrm{~km}^{-1}$ or lower are well encapsulated within the optimised thresholds where the traditional fixed CI-A method would fail. This system proves to be an invaluable tool for the detection of pollution events where clouds and aerosols can have an important role in the chemical processes in the UTLS, affect the radiative properties of the stratosphere (Kravitz and Robock, 2011) or compromise transport safety (for example, volcanic ash emission affecting aircraft engines; Prata et al., 2008).

Acknowledgements. The work done in this study was supported by ESA through the MIPclouds project: "Cloud Information Retrieval from MIPAS Measurements", AO/1-5255/06/I-OL. The authors would like to acknowledge the MIPAS Quality Working Group, Michael Fromm and Hugh Pumphrey for scientific discussions specific to this study.

Edited by: J. Cermak

\section{References}

Bourassa, A. E., Degenstein, D. A., and Llewellyn, E. J., Climatology of the subvisual cirrus clouds as seen by OSIRIS on Odin, Adv. Space Res., 36, 807-812, 2005.

Bourassa, A. E., Degenstein, D. A., Elash, B. J., and Llewellyn, E. J.: Evolution of the stratospheric aerosol enhancement following the eruptions of Okmok and Kasatochi: OdinOSIRIS measurements, J. Geophys. Res., 115, D00L03, doi:10.1029/2009JD013274, 2010.

Clarisse, L., Coheur, P. F., Prata, A. J., Hurtmans, D., Razavi, A., Phulpin, T., Hadji-Lazaro, J., and Clerbaux, C.: Tracking and quantifying volcanic $\mathrm{SO}_{2}$ with IASI, the September 2007 eruption at Jebel at Tair, Atmos. Chem. Phys., 8, 7723-7734, doi:10.5194/acp-8-7723-2008, 2008.

Corti, T., Luo, B. P., Peter, T., Vömel, H., and Fu, Q.: Mean radiative energy balance and vertical mass fluxes in the equatorial upper troposphere and lower stratosphere, Geophys. Res. Lett., 32, L06802, doi:10.1029/2004GL021889, 2005.

CSIRO: Q \& A - Victorian Bushfires, available at: http: //www.csiro.au/resources/Victorian-Bushfires-QA (last access: January 2012), 2011.

de Laat, A. T. J, Stein-Zweers, D. C., Boers, R., and Tuinder, O. N. E.: A solar escalator: observational evidence of the self-lifting of smoke and aerosols by absorption of solar radiation in the February 2009 Australian Black Saturday plume, J. Geophys. Res., 117, D04204, doi:10.1029/2011JD017016, 2012.
Draxler, R. R. and Rolph, G. D.: HYSPLIT (HYbrid Single-Particle Lagrangian Integrated Trajectory) Model access via NOAA ARL READY Website (http://ready.arl.noaa.gov/HYSPLIT. php), NOAA Air Resources Laboratory, Silver Spring, MD, 2012.

Dudhia, A.: The Oxford Reference Forward Model, available at: http://www.atm.ox.ac.uk/RFM/ (last access: January 2012), 2005.

Eichmann, K-U., von Savigny, C., Reichl, P., Robert, C., Steinwagner, J., Bovensmann, H., and Burrows, J. P.: SCODA: SCIAMACHY Cloud detection algorithm from limb radiance measurements, ATBD version 2.0, 2009.

Fischer, H., Birk, M., Blom, C., Carli, B., Carlotti, M., von Clarmann, T., Delbouille, L., Dudhia, A., Ehhalt, D., Endemann, M., Flaud, J. M., Gessner, R., Kleinert, A., Koopman, R., Langen, J., López-Puertas, M., Mosner, P., Nett, H., Oelhaf, H., Perron, G., Remedios, J., Ridolfi, M., Stiller, G., and Zander, R.: MIPAS: an instrument for atmospheric and climate research, Atmos. Chem. Phys., 8, 2151-2188, doi:10.5194/acp-8-2151-2008, 2008.

Forster, P., Ramaswamy, V., Artaxo, P., Berntsen, T., Betts, R., Fahey, D. W., Haywood, J., Lean, J., Lowe, D. C., Myhre, G., Nganga, J., Prinn, R., Raga, G., Schulz M., and Van Dorland, R.: Changes in Atmospheric Constituents and in Radiative Forcing, in: Climate Change 2007: The Physical Science Basis. Contribution of Working Group I to the Fourth Assessment Report of the Intergovernmental Panel on Climate Change, edited by: Solomon, S., Qin, D., Manning, M., Chen, Z., Marquis, M., Averyt, K. B., Tignor, M., and Miller, H. L., Cambridge University Press, Cambridge, United Kingdom and New York, NY, USA, 2007.

Frey, R. A., Ackerman, S. A., Liu, Y., Strabala, K. I., Zhang, H., Key, J. R., and Wang, X.: Cloud Detection with MODIS Part 1: Improvements in the MODIS cloud mask for Collection 5, J. Atmos. Ocean. Tech., 25, 1057-1072, 2008.

Fromm, M., Tupper, A., Rosenfeld, D., Servranckx, R., and McRae, R.: Violent pyro-convective storm devastates Australia's capital and pollutes the stratosphere, Geophys. Res. Lett., 33, L05815, doi:10.1029/2005GL025161, 2006.

Gille, J., Gray, L., Cavanaugh, C., Choi, K. Y., Coffey, M., Craig, C., Karol, S., Hepplewhite, C., Khosravi, R., Kinnison, D., Massie, S., Nardi, B., Rivas, M. B., Smith, L., Waterfall, A., and Wright, C.: HIRDLS High Resolution Dynamics Limb Sounder, Earth Observing System (EOS) Data Description and Quality Version 6 (V6), SC-HIR-1511F, 2011.

Greenhough, J., Remedios, J. J., Sembhi, H., and Kramer, L. J.: Towards cloud detection and cloud frequency distributions from MIPAS infrared observations, Adv. Space Res., 36, 800-806, 2005.

Hervig, M. and McHugh, M.: Cirrus Detection using HALOE Measurements, Geophys. Res. Letts, 26, 719-722, 1999.

Höpfner, M., Oelhaf, H., Wetzel, G., Friedl-Vallon, F., Kleinert, A., Lengel, A., Maucher, G., Nordmeyer, H., Glatthor, N., Stiller, G., von Clarmann, T., Fischer, H., Kröger, C., and Deshler, T.: Evidence of scattering of tropospheric radiation by PSCs in mid-IR limb emission spectra: MIPAS-B observations and KOPRA simulations, Geophys. Res. Lett., 29, 1278, doi:10.1029/2001GL014443, 2002.

Höpfner, M., Larsen, N., Spang, R., Luo, B. P., Ma, J., Svendsen, S. H., Eckermann, S. D., Knudsen, B., Massoli, P., Cairo, F., Stiller, 
G., v. Clarmann, T., and Fischer, H.: MIPAS detects Antarctic stratospheric belt of NAT PSCs caused by mountain waves, Atmos. Chem. Phys., 6, 1221-1230, doi:10.5194/acp-6-1221-2006, 2006.

Höpfner, M., Pitts, M. C., and Poole, L. R.: Comparison between CALIPSO and MIPAS observations of polar stratospheric clouds, J. Geophys. Res., 114, D00H05, doi:10.1029/2009JD012114, 2009.

Hurley, J., Dudhia, A., and Grainger, R. G.: Retrieval of macrophysical cloud parameters from MIPAS: algorithm description, Atmos. Meas. Tech., 4, 683-704, doi:10.5194/amt-4-683-2011, 2011.

Jensen, E. J., Toon, O. B., Selkirk, H. B., Spinhirne, J. D., and Schoeberl, M. R.: On the formation and persistence of subvisible cirrus clouds near the tropical tropopause, J. Geophys. Res., 101, 21361-21375, 1996a.

Jensen, E. J., Toon, O. B., Pfister, L., and Selkirk, H. B.: Dehydration of the upper troposphere and lower stratosphere by subvisible cirrus clouds near the tropical tropopause, Geophys. Res. Lett., 23, 825-828, 1996b.

Kalnay, E., Kanamitsu, M., Kistler, R., Collins, W., Deaven, D., Gandin, L., Iredell, M., Saha, S., White, G., Woollen, J., Zhu, Y., Chelliah, M., Ebisuzaki, W., Higgins, W., Janowiak, J., Mo, K., Ropelewski, C., Wang, J., Leetmaa, A., Reynolds, R., Jenne, R., and Joseph, D.: The NCEP/NCAR 40-year reanalysis project, B. Am. Meteorol. Soc., 77, 437-471, 1996.

Karagulian, F., Clarisse, L., Clerbaux, C., Prata, A. J., Hurtmans, D., and Coheur, P. F.: Detection of volcanic $\mathrm{SO}_{2}$, ash, and $\mathrm{H}_{2} \mathrm{SO}_{4}$ using the Infrared Atmospheric Sounding Interferometer (IASI), J. Geophys. Res., 115, D00L02, doi:10.1029/2009JD012786, 2010.

Kent, G. S., Winker, D. M., Osborn, M. T., and Skeens, K. M.: A model for the separation of cloud aerosol in SAGE II occultation data, J. Geophys. Res., 98, 725-735, 1993.

Kiefer, M., von Clarmann, T., Grabowski, U., De Laurentis, M., Mantovani, R., Milz, M., and Ridolfi, M.: Characterization of MIPAS elevation pointing, Atmos. Chem. Phys., 7, 1615-1628, doi:10.5194/acp-7-1615-2007, 2007.

Kleinert, A., Aubertin, G., Perron, G., Birk, M., Wagner, G., Hase, F., Nett, H., and Poulin, R.: MIPAS Level 1B algorithms overview: operational processing and characterization, Atmos. Chem. Phys., 7, 1395-1406, doi:10.5194/acp-7-13952007, 2007.

Kravitz, B. and Robock, A.: The climate effects of high latitude eruptions: The role of the time of year, J. Geophys. Res., 116, D01105, doi:10.1029/2010JD014448, 2011.

Kristiansen, N. I., Stohl, A, Prata, A.J, Richter, A., Eckhardt, S., Seibert, P., Hoffmann, A., Ritter, C., Bitar, L., Duck, T. J., and Stebel, K.: Remote sensing and inverse transport modelling of the Kasatochi eruption sulphur dioxide cloud, J. Geophys. Res., 115, D00L16, doi:10.1029/2009JD013286, 2010.

Liu, C., Zipser, E. J., and Nesbitt, S.: Global distribution of tropical deep convection: Different perspectives from TRMM infrared and radar data, J. Climate, 20, 480-503, 2007.

Manney, G. L., Santee, M. L., Rex, M., Livesey, J., Pitts, M. C., Veefkind, P., Nash, E. R., Wohltmann, I., Lehmann, R., Froidevaux, L., Poole, L. R., Schoeberl, M. R., Haffner, D. P., Davies, J., Dorokhov, V., Gernandt, H., Johnson, B., Kivi, R., Kyrö, E., Larsen, N., Levelt, P., Makshtas, A., McElroy, C. T., Nakajima,
H., Parrondo, A. C., Tarasick, D. W., von der Gathen, P., Walker, K. A., and Zinoviev, N. S.: Unprecedented Arctic ozone loss in 2011, Nature, 489, 469-473, 2011.

Massie, S., Gille, J., Khosravi, R., Lee, H., Kinnison, D., Francis, G., Nardi, B., Eden, T., Craig, C., Halvorson, C., Coffey, M., Packman, D., Cavanaugh, C., Craft, J., Dean, V., Ellis, D., Barnett, J., Hepplewhite, C., Lambert, A., Manney, G., Strawa, A., and Legg, M.: High Resolution Dynamics Limb Sounder observations of polar stratospheric clouds and subvisible cirrus, J. Geophys. Res., 112, D24S31, doi:10.1029/2007JD008788, 2007.

Massie, S. T., Gille, J., Craig, C., Khosravi, R., Barnett, J., Read, W., and Winker, D., HIRDLS and CALIPSO observations of tropical cirrus, J. Geophys. Res., 115, D00H11, doi:10.1029/2009JD012100, 2010.

Mergenthaler, J., Roche, A. E., Kumer, J. B., and Ely, G.: Cryogenic Limb Array Etalon Spectrometer observations of tropical cirrus, J. Geophys. Res., 104, 22183-22194, 1999.

Milz, M., von Clarmann, T., Fischer, H., Glatthor, N., Grabowski, U., Höpfner, M., Kellmann, S., Kiefer, M., Linden, A., Mengistu Tsidu, G., Steck, T., Stiller, G. P., Funke, B., López-Puertas, M., and Koukouli, M. E.: Water vapour distributions measured with the Michelson Interferometer Passive Atmospheric Sounding on board ENVISAT (MIPAS/ENVISAT), J. Geophys. Res., 110, D24307, doi:10.1029/2005JD005973, 2005.

Moore, D. P. and Remedios, J. J.: Growth rates of stratospheric HCFC-22, Atmos. Chem. Phys., 8, 73-82, doi:10.5194/acp-873-2008, 2008.

Moore, D. P., Remedios, J. J., and Waterfall, A. M.: Global distributions of acetone in the upper troposphere from MIPAS spectra, Atmos. Chem. Phys., 12, 757-768, doi:10.5194/acp-12-7572012, 2012.

Prata, A. F.: Satellite detection of hazardous volcanic clouds and the risk to global air traffic, Nat. Hazards, Prata, A.J., 2009, Satellite detection of hazardous volcanic clouds and the risk to global air traffic: Natural Hazards, 51, 303-324, doi:10.1007/s11069-0089273-z, 2008.

Prata, A. J., Carn, S. A., Stohl, A., and Kerkmann, J.: Long range transport and fate of a stratospheric volcanic cloud from Soufrière Hills volcano, Montserrat, Atmos. Chem. Phys., 7, 5093-5103, doi:10.5194/acp-7-5093-2007, 2007.

Prata, A. J., Gangale, G., Clarisse, L., and Karagulian, F.: Ash and sulphur dioxide in the 2008 eruptions of Okmok and Kasatochi: Insights from high spectral resolution satellite measurements, J. Geophys. Res, 115, D00L18, doi:10.1029/2009JD013556, 2010.

Pumphrey, H. C., Santee, M. L., Livesey, N. J., Schwartz, M. J., and Read, W. G.: Microwave Limb Sounder observations of biomassburning products from the Australian bush fires of February 2009, Atmos. Chem. Phys., 11, 6285-6296, doi:10.5194/acp-116285-2011, 2011.

Randall, D. A., Wood, R. A, Bony, S., Colman R., Fichefet, T., Fyfe, J., Kattsov, V., Pitman, A., Shukla, J., Srinivasan, J., Stouffer, R. J., Sumi, A., and Taylor, K. E.: Climate Models and Their Evaluation, in: Climate Change 2007: The Physical Science Basis, Contribution of Working Group I to the Fourth Assessment Report of the Intergovernmental Panel on Climate Change, edited by: Solomon, S., Qin, D., Manning, M., Chen, Z., Marquis, M., Averyt, K. B., Tignor, M., and Miller, H. L., Cambridge University Press, Cambridge, United Kingdom and New York, NY, USA, 2007. 
Raspollini, P., Belotti, C., Burgess, A., Carli, B., Carlotti, M., Ceccherini, S., Dinelli, B. M., Dudhia, A., Flaud, J.-M., Funke, B., Höpfner, M., López-Puertas, M., Payne, V., Piccolo, C., Remedios, J. J., Ridolfi, M., and Spang, R.: MIPAS level 2 operational analysis, Atmos. Chem. Phys., 6, 5605-5630, doi:10.5194/acp6-5605-2006, 2006.

Remedios, J. J., Leigh, R. J., Waterfall, A. M., Moore, D. P., Sembhi, H., Parkes, I., Greenhough, J., Chipperfield, M. P., and Hauglustaine, D.: MIPAS reference atmospheres and comparisons to V4.61/V4.62 MIPAS level 2 geophysical data sets, Atmos. Chem. Phys. Discuss., 7, 9973-10017, doi:10.5194/acpd-79973-2007, 2007.

Robock, A.: Volcanic eruptions and climate, Rev. Geophys., 38, 191-219, 2000.

Siddaway, J. M. and Petelina, S. V.: Transport and evolution of the 2009 Australian Black Saturday bushfire smoke in the lower stratosphere observed by OSIRIS on Odin, J. Geophys. Res., 116, D06203, doi:10.1029/2010JD015162, 2011.

Sioris, C. E., Boone, C. D., Bernath, P. F., Zou, J., McElroy, C. T., and McLinden, C. A.: Atmospheric Chemistry Experiment (ACE) observations of aerosol in the upper troposphere and lower stratosphere from the Kasatochi volcanic eruption, J. Geophys. Res., 115, D00L14, doi:10.1029/2009JD013469, 2010.

Spang, R. and Remedios, J. J.: Observations of a distinctive infrared spectral feature in the atmospheric spectra of polar stratospheric clouds measured by the CRISTA instrument, Geophys. Res. Lett., 30, 1875, doi:10.1029/2003GL017231, 2003.

Spang, R., Riese, M., Eidmann, G., Offermann, D., Pfister, L., and Wang, P. H.: CRISTA observations of cirrus clouds around the tropopause, J. Geophys. Res., 107, 8174, doi:10/1029/2002JD000698, 2002.

Spang, R., Remedios, J. J., and Barkley, M. P.: Colour indices for the detection and differentiation of cloud types in infrared limb emission spectra, Adv. Space Res., 33, 1041-1047, 2004.

Spang, R., Arndt, K., Dudhia, A., Höpfner, M., Hoffmann, L., Hurley, J., Grainger, R. G., Griessbach, S., Poulsen, C., Remedios, J. J., Riese, M., Sembhi, H., Siddans, R., Waterfall, A., and Zehner, C.: Fast cloud parameter retrievals of MIPAS/Envisat, Atmos. Chem. Phys., 12, 7135-7164, doi:10.5194/acp-12-71352012, 2012.
Strabala, K. I., Ackerman, S. A., and Menzel, W. P.: Cloud properties inferred from 8-12 micron data, J. Appl. Meteor., 33, 212229, 1994.

Stephens, G.: Remote Sensing of the Lower Atmosphere: An Introduction, Oxford Univ. Press, March 1994.

Vaughan, M., Young, S., Winker, D., Powell, K., Omar, A., Liu, Z., Hu, Y., and Hostetler, C.: Fully automated analysis of spacebased lidar data: an overview of the CALIPSO retrieval algorithms and data products, Proc. SPIE, 5575, 16-30, 2004.

Vömel, H.: Saturation Vapour Pressure Formulations, available at: http://cires.colorado.edu/ $\sim$ voemel/vp.html (last access: January 2012), 2011.

Waythomas, C. F., Scott, W. E., Prejean, S. G., Schneider, D. J., Izbekov, P., and Nye, C. J.: The 7-8 August 2008 eruption of Kasatochi Volcano, central Aleutian Islands, Alaska, J. Geophys. Res., 115, B00B06, doi:10.1029/2010JB007437, 2010.

Weisz, E., Li, J., Menzel, W. P., Heidinger, A. K., Kahn, B. H., and Li, C.-Y.: Comparison of AIRS, MODIS, CloudSat and CALIPSO cloud top height retrievals, Geophys. Res. Lett., 34, L17811, doi:10.1029/2007GL030676, 2007.

Winker, D. M., Hostetler, C. A., Vaughan, M. A., and Omar, A. H.: CALIOP Algorithm Theoretical Basis Document: Part 1. CALIOP instrument and Algorithms Overview, PC-SCI-202, Part 1, Release 2.0, 2006.

Winker, D. M., Hunt, W. H., and McGill, M. J.: Initial performance assessment of CALIOP, Geophys. Res. Lett., 34, L19803, doi:10.1029/2007GL030135, 2007.

Winker, D. M., Pelon, J., Coakley, J. A., Ackerman, S. A, Charlson, R. J., Colarco, P. R., Flamant, P., Fu, Q., Hoff, R. M., Kittaka, C., Kubar, T. L., LeTreut, H., McCormick, M. P., Megie, G., Poole, L., Powell, K., Trepte, C., Vaughan, M. A., and Wielicki, B. A.: The CALIPSO Mission: A Global 3D View of Aerosols and Clouds, J. B. Am. Meteorol. Soc., 1211-1229, doi:10.1175/2010BAMS3009.1, 2010.

Wu, D. L. and Jiang, J. H.: EOS MLS Algorithm Theoretical Basis for Cloud Measurements, Technical Report, D-19299, Jet Propulsion Laboratory, 2004. 